Portland State University

PDXScholar

Winter 2-23-2018

\title{
Organizational Calling and Safety: the Role of Workload and Supervisor Support
}

Layla Rhiannon Mansfield

Portland State University

Follow this and additional works at: https://pdxscholar.library.pdx.edu/open_access_etds

Part of the Psychology Commons

Let us know how access to this document benefits you.

Recommended Citation

Mansfield, Layla Rhiannon, "Organizational Calling and Safety: the Role of Workload and Supervisor Support" (2018). Dissertations and Theses. Paper 4234.

https://doi.org/10.15760/etd.6118

This Dissertation is brought to you for free and open access. It has been accepted for inclusion in Dissertations and Theses by an authorized administrator of PDXScholar. Please contact us if we can make this document more accessible: pdxscholar@pdx.edu. 
Organizational Calling and Safety:

The Role of Workload and Supervisor Support

by

Layla Rhiannon Mansfield

A dissertation submitted in partial fulfillment of the requirements for the degree of

Doctor of Philosophy

in

Applied Psychology

Dissertation Committee:

Talya N. Bauer, Chair

Todd Bodner

Leslie B. Hammer

Donald M. Truxillo

Wayne Wakeland

Portland State University

2018 
C 2017 Layla Rhiannon Mansfield 
Abstract

Research suggests that individuals who perceive their work as a calling (a deep passion and meaningfulness associated with a certain domain) experience a variety of positive outcomes such as occupational identification, career decidedness, and job satisfaction. Utilizing the tenets of Social Exchange Theory and the Job Demands Resources Model, I proposed that individuals with greater calling toward their occupation will report higher safety motivation and safety compliance. However, under conditions of high workload this relationship would be attenuated. Further, by the same rationale, individuals with lower calling will report lower safety outcomes, yet I proposed that this relationship is mitigated under conditions of high supervisor support. The study was conducted with a sample of 183 participants collected across three forests within the United States Forest Service. Although the hypotheses in the study were not supported, this study provides theoretical groundwork elucidating the link between calling and the examined outcome safety. This, in turn, will aid in the development of a number of potential research avenues for safety scholars, with many practical implications. Further, an examination of calling with other collected variables within this industry provides avenues for future research in the calling domain. The investigation of moderators may help to explain the conflicting results found in the calling literature. Finally, this study furthers our understanding of safety, workload, and supervisor support within a "helping field." 
Acknowledgments

I am particularly grateful for the support given by Portland State University's School of Business and Department of Psychology throughout my graduate school career. My graduate education was also supported by Graduate Training in Occupational Health Psychology Grant (Grant \# T03OH008435). I thank the Oregon Healthy Workforce Center, a NIOSH Total Worker Health Center of Excellence, for supporting this dissertation study (Grant \# U19OH010154). I also thank Drs. Truxillo, Hammer, Bodner, and Wakeland for their valuable and constructive suggestions on this research work as well as their guidance throughout my graduate education. A very special shout-out to my primary advisor Dr. Talya Bauer for her patient guidance and enthusiastic encouragement throughout my education - her support never wavered even in the face of conflicting evidence. I cannot thank you enough. Finally, I thank the Unites States Forest Service (USFS) Region 6 leadership for their support of this study and all of the USFS employees who allowed me into their work lives to explore my research questions. 
Table of Contents

$\begin{array}{lr}\text { Abstract } & \text { i } \\ \text { Acknowledgements } & \text { ii } \\ \text { List of Tables } & \text { iv } \\ \text { List of Figures } & \\ \text { Chapter 1 } & 1 \\ \text { Introduction } & \text { V }\end{array}$

Chapter 2

Calling

Chapter 3

Potential Moderators of the Relationship Between Calling and Safety

Chapter 4

Safety Motivation and Safety Compliance

Chapter 5

Theory

Chapter 6

Hypotheses

Chapter 7

Method

Chapter 8

Results

Chapter 9

Discussion

References

Appendices

Appendix A: Interview Questions and Job Shadow Protocol 
Table 2. Participant demographics 96

$\begin{array}{lll}\text { Table 3. Participant job characteristics } & 97\end{array}$

Table 4. Means, standard deviations, and correlations of study variables 98

Table 5. Model summary and parameter estimates for the interaction between calling and workload predicting safety motivation

Table 6. Model summary and parameter estimates for the interaction between calling and workload predicting safety compliance

Table 7. Model summary and parameter estimates for the interaction between calling and supervisor support predicting safety motivation

Table 8. Model summary and parameter estimates for the interaction between calling and supervisor support predicting safety compliance

Table 9. Model summary and parameter estimates for the three-way interaction between calling, workload, and supervisor support predicting safety motivation

Table 10. Model summary and parameter estimates for the three-way interaction between calling, workload, and supervisor support predicting safety compliance 
List of Figures

$\begin{array}{ll}\text { Figure 1. Conceptual Model } & 105\end{array}$ 
Chapter 1

Introduction

A tremendous cost is placed on employers, workers, and society in workers' compensation, medical expenses, lost wages and productivity, due to occupational injuries and illnesses. One economic analysis suggested that occupational deaths and injuries cost the nation $\$ 192$ billion annually, including direct medical costs and indirect costs such as lost wages and productivity (Leigh, 2011). Given the economic and personal cost associated with injuries and accidents, there is much to gain by investigating the factors that affect workplace safety. Accordingly, there has been a rise in research on occupational safety. For example, a basic search in PsycInfo of the key term "occupational safety" yielded a total of 967 records in the years 1910 to 1999 , whereas in the years 2000 to 2017 the same search found a total of 4,100 records indicating a quadrupling of research in the last 17 years. This increased research attention is further evidenced by the several meta-analyses (e.g., Beus, Dhanani, \& McCord, 2015; Beus, Payne, Bergman, \& Arthur, 2010; Christian, Bradley, Wallace, \& Burke, 2009; Clarke, 2006; Clarke \& Robertson, 2005; Nahrgang, Morgeson, \& Hofmann, 2011) and literature reviews (Burke \& Signal, 2010; Hoffman, Burke, \& Zohar, 2017; Kaplan \& Tetrick, 2011; Wallace, Paul, Landis, \& Vodanovich, 2012) published in recent years. Although the literature and our knowledge has increased, accidents and injuries remain a concern. For example, in the State of Oregon, 737 workers were fatally injured in the years from 2003-2015 (Oregon Fatality Assessment \& Control Evaluation, 2014), these are people who went to work and, due to any number of factors, either did not 
return home or were injured so badly during the course of their workday that they eventually lost their lives. Thus, while there appears to be a boom in safety research, it is imperative that more be done to identify proactive factors that may save lives. The purpose of this dissertation is to study an unexamined factor, "calling", regarding its role in occupational safety. However, it is not yet clear if calling helps, hurts, or is unrelated to safety overall and the conditions that may determine its role. This dissertation attempts to clarify the relationship.

Calling is a construct that investigates the way individuals see our work roles and is embedded in the work orientation literature. The work orientation literature is founded upon the idea that some people value their occupations with respect to how well it contributes to a greater sense of personal purpose. Alternatively, some people prefer to compartmentalize their work as simply a means of providing income. These appraisals of work have been defined and categorized as a calling, career, or job (Wrzesniewski, McCauley, Rozin, \& Schwartz, 1997). Individuals who maintain a "calling” work orientation feel that the tasks they engage in at work fulfill their life's purpose, and that they would experience a personal void in the event that they could no longer serve in this capacity. Employees with a "career" work orientation are primarily concerned with their personal advancement in their current line of work; they tend to be motivated by the status and fulfillment associated with promotions. Lastly, employees who report having a "job" work orientation see their work simply as a means for fulfilling their financial obligations, to "pay the bills" or "put food on the table." Studying the construct of calling has recently garnered the attention of researchers from a variety of disciplines, perhaps 
because they are recognizing the complexities and implications that an employee's view of their work has on performance, satisfaction, and well-being outcomes. For example, researchers have found positive effects of calling on work-related outcomes such as job satisfaction and organizational commitment and it has been argued that organizational interventions should be designed to help individuals to discover their calling. These interventions could be designed to enhance individuals' openness to new directions, to encourage individuals to explore their interests, values, and skills and match them with potential jobs or to encourage individuals to connect their work with a tangible, prosocially-oriented purpose (Duffy \& Dik, 2013). Second, individuals with a calling are strongly motivated to enter and remain in environments that help them to fulfill their calling (Bunderson \& Thompson, 2009; Dobrow \& Heller, 2015). This dissertation will add to this burgeoning literature on calling by attempting to answer three research questions aimed at understanding if it makes sense to harness calling to impact employee safety motivation and safety compliance.

\section{Study Overview}

Calling is a relatively new construct in the organizational sciences and as such there are still a number of potential research streams. This dissertation aims to bridge the literature on calling with that of the occupational health field. In doing so I will investigate the role that calling has on two safety outcomes, safety motivation and safety compliance. Thus, my first research question asks -Are those who feel called to their positions more likely to espouse workplace safety? The link between calling and safety is 
not clear in the calling literature. Hence one might ask of all the yet-to-be investigated outcomes of calling, why safety?

There is literature to suggest this link. It has been argued that those pursuing their callings have a complete devotion to the activities that encompass their calling activities that may go beyond assigned goals, expectations and rewards. The effort and behaviors of those pursuing their calling are not limited to official requirements and their all-consuming passion for their calling often drives them to perform over and above the call of duty (Elangovan, Pinder, \& McLean, 2010). For example, Praskova, Creed, and Hood (2015) found that calling was associated with higher work effort, indicating that those with higher calling are willing to put in the necessary effort to reach their goals. Thus, my argument is that when safety is a key organizational goal employees experiencing a calling will inherently espouse this same goal and work hard to accomplish it. Of course, those with a high calling do not necessarily need to embrace organizational goals but there is literature to suggest that those with higher calling may be more likely to identify with their organization (Bunderson \& Thompson, 2009; Hirschi, 2012) and remain committed to the organization (Duffy, Bott, Allan, \& Autin, 2015; Rawat \& Nadavulakere, 2015). In sum, although the direct relationship between calling and safety performance has yet to be investigated, there is peripheral literature to suggest this potential link. Still, a bridge is needed to make the leap from calling to safety. This bridge came from the findings of this study's pilot work.

This study took place within the United States Forest Service (USFS) as part of larger study conducting a needs-assessment with the goal of developing a workplace 
intervention. The calling construct was highlighted throughout the pilot study. The participants and the procedure for the pilot work are further described in Chapter 7, the Method chapter (see Appendix A for the interview questions and the job shadow protocol). For example, leadership remarked on the high "commitment" of their "folks" and the desire to work beyond the core job tasks. Further, these meetings commented on the high culture of safety within the organization. This participant quote from the pilot work further evidences the value of the work and safety within the USFS.

"In addition to mandated safety and health, we are all personally responsible [...] it comes back to the individual to be safe and healthy. It is pretty awesome to be entrusted with the work within [job place]. I get to work with teams of experts, who are highly knowledgeable in their areas... I am fortunate to have a job where I can go in the field voluntarily, to help -ologists, (the term "ologist" encapsulates those in research). I love the people and the land. I'm blessed to have a job where I can work with people who have a depth of knowledge in the land. Taking care of the forest is something I take very seriously."

This participant obviously held a passion toward their job and further, also found safety and health to be an important aspect of their role within the USFS. This is just one participant, but these statements of high passion and high commitment to safety were a recurring theme in most of the pilot work. Although the pilot work was conducted as a needs assessment rather than a true qualitative analysis (e.g., Glaser \& Strauss, 1967), this work allowed for a unique glimpse into the relationships proposed in this study within the USFS. 
Thus far, I have given a brief overview into the calling literature as it may relate to safety, and I have provided an example of the pilot work. In Chapter 2, the Calling chapter, I will go into more depth on the calling literature. I will discuss the myriad of definitions within the literature, I will give an overview of the antecedents and outcomes of calling and I will review the literature on what may be called the "dark side of calling". And it is this - the dark side of calling that justifies my second research question. The below quote from a USFS participant highlights the direction of my second research question;

"The desire to be in the woods and manage national lands really brings a person to this job. With the same education level, you can make 100 grand per year doing something else, but this is what I'm meant to do. The passion bears a fine line, though. You can burn yourself out."

The literature on calling recognizes that calling may come with some negative outcomes. For example, calling was found to be both "wonderfully fulfilling" and "personally draining” (Serow, 1994, p. 68) in a sample of teachers. Further, a deep sense of calling has been linked to burnout (Vinje \& Mittelmark, 2007) and unnecessary stress and interpersonal conflict (Cardador \& Caza, 2012) as a result of unrealistic performance expectations of self and others. Thus, there appears to be a relationship between calling and negative outcomes and yet, overwhelmingly calling appears to be associated with positive outcomes. For example, research has shown that callings are positively related to well-being, such that people with callings are more likely to report life satisfaction (Duffy, Manuel, Borges, \& Bott, 2011) and less likely to suffer depression (Treadgold, 
1999). Furthermore, the theories typically used to describe the role of calling (e.g., work orientation theory, role investment theory, meaningful work as situated within job characteristics model) have positioned calling so that positive outcomes seem almost intuitive. If so, what is contributing to these negative outcomes? Are there certain conditions or populations in which calling leads to negative outcomes? This line of thinking lends to my second research question - What is the role of workload in the relationship between calling and safety? Could workload moderate this relationship such that under conditions of high workload the positive relationship that we may see between calling and safety is diminished? Workload as a moderating variable was selected for two reasons.

First, it has been argued that those who feel called to their position/jobs are more likely to set high expectations for themselves and their organizations (Vinje \& Mittelmark, 2007), are more likely to work outside their prescribed work roles (i.e., participate in organizational citizenship behaviors, Park, Sohn, \& Ha 2016), and are more likely to craft their jobs so that it fulfills their own personal goals (Berg, Grant, \& Johnson, 2010). Although not directly studied, the underlying assumption within these relationships is that those with higher calling orientations may be taking on more work than necessary and thus be prone to high workloads. It is beyond this study to assess whether the source of workload is organizational or personal but the expected moderating relationship is retained no matter the source. The below quote from a supervisor in the pilot work highlights the employee as the potential source of workload; she says, 
“Employees often mention that they don't have enough time to do their work. Certain individuals have more on their plate than is reasonable. The workforce is very committed to their work. People will work more than is good for them. I hope they're putting it down on their time sheet, but part of me wonders if that is the case. I want to make sure people take the time off that they need." Furthermore, when looking at organizational assigned workload, there were a number of quotes exemplifying that high workload may be prevalent within the USFS. For example, “I probably don't have enough time to get my work done. It's a 'can do' or 'will do' organization" or "there has been a reduction in numbers, but the same number of acres. With the budgetary and time constraints, people feel there is more work than time to do it. People are struggling to balance the overwhelming workload.” In sum, looking at workload makes both practical sense so to inform the sample population of the potential risks associated with high workload, and also theoretical sense in that we can investigate a contextual variable that may contribute to the conflicting results found in the calling literature.

I will define workload in Chapter 3, the Moderators chapter. In this same chapter I will also take a broader look at the second moderating factor in the relationship between calling and safety, supervisor support.

Supervisor support was selected as a variable of interest due to its presence or lack of in the sample in which the pilot work took place. For example, an employee in the USFS stated, "I used to have more support but with the reduction in staff and the fact that my supervisors have left, I am basically on my own. I asked vehemently for more support 
and did get it for specific issues but it is not constant. I used to have monthly meetings with supervisor but not anymore."

Furthermore, when looking at what is missing in the calling literature, most studies have examined what has occurred under conditions of high calling, not low calling (for an exception see Cardador, Dane, \& Pratt 2011). Calling is not simply something you have or do not have (i.e., it is not a binary variable), thus employees may report low or high calling orientation. Thus far, I have predicted that those with high levels of calling orientation will have high levels of safety motivation and safety compliance. This implies that those with low levels of calling orientation should have low levels of safety motivation and compliance. This possibility raises an important question: How can organizations enhance what might otherwise be relatively low levels of safety among employees who lack a strong calling orientation? Thus, with the second moderating factor I shift my focus away from why high levels of calling foster safety and toward the question of what can be done to cultivate safety among those with low levels of calling. My third research question asks - What is the role of the supervisor in the relationship between calling and safety?

The role of the supervisor in workplace safety has been investigated previously. For example, the effects of an intervention focused on the reduction of work-life conflict on safety compliance was found to be moderated by supervisor support for family and non-work life such that the intervention was more effective if supervisors exhibited supportive behaviors (Hammer et al., 2016). Further research shows that consistent, effective leadership (e.g., transformational leadership) can lead to higher levels of safety 
compliance (Innes, Turner, Barling, \& Stride, 2010; Mullen, Kelloway, \& Teed, 2011), whereas leader-member exchange was found to be related to safety communication, safety commitment and reduced accidents (Hofmann \& Morgeson, 1999). Therefore, the literature tends to support the notion that supervisor support can impact safety outcomes.

In sum, this study has proposed a relationship between calling and safety. Further, the role of the moderating variables will form different relationships with those who identify with a high calling orientation compared to those with a low calling orientation. These research questions mirror onto specific hypotheses that are made explicit in Chapter 6 the Hypotheses chapter. This study will investigate the impact of calling on safety motivation and safety compliance, and the moderating effects of workload and supervisor support on this relationship. Thus far, I have described my research questions and couched them in the current literature. I have also utilized the results on the pilot data to build a case for the importance and possible relationships between the constructs (see Figure 1 for the conceptual model in this study).

Investigating these research questions serves to fill three important gaps in the literature. First, this study will help to elucidate the link between calling and an examined outcome safety. By investigating this link this study illuminates a potential trajectory in the calling literature by showing how organizational and personal goals may align. Furthermore, by investigating this link, this study adds to what we know about organizational safety. Finding a link between calling and safety will aid in the development of several potential research avenues for safety scholars, which as noted above can have several practical implications. 
Second, this study also examines the moderating factors of workload and supervisor support. The investigation of moderators may help to explain the conflicting results found in the calling literature. Finally, this study will further our understanding of safety, workload, and supervisor support within an important context of a helping field. The sample targeted for this study are those in helping roles such as forestry work. A helping field is one that provides meaningful work that also serving society, and while examples typically include nursing, social work, or public health, I argue here that those that work for the USFS would also fall into this category. As an example, the USFS's motto is "Caring for the Land and Serving People," and is further explicated in their mission to sustain the health, diversity, and productivity of the nation's forests and grasslands to meet the needs of present and future generations. The aims of the study are reviewed in further detail in Chapter 9, the Discussion chapter. 


\section{Chapter 2}

\section{Calling}

The interest in understanding more about the experience of work is bred from the fact that we spend an enormous amount of our lives working. Thus, our working lives can have tremendous impact not only on our non-working lives but also in the way we see ourselves. Work has such a role in our identity that even at young ages when we envision our adulthood, the guiding question is, "what will you be when we grow up?" Yet this question does not end after childhood. In adulthood, we ebb and flow in our careers often questioning the reasons for accepting or rejecting positions and careers. Some individuals may find themselves preoccupied with the discovery of purpose and meaning alongside the pursuit of work and in many cases this pursuit takes people beyond the mere extrinsic gain of a position. Why? What draws or guides these individuals to engage in work beyond monetary compensation? Could there be a connection between one's values and their chosen career? These questions have plagued researchers for many years and finding the answers to these questions has led to numerous research trajectories. One such research stream is the concept of calling. The subject, while having been explored for centuries, has recently received renewed attention in scholarly literature and because of the resurgence of the topic, new perspectives of how one connects to the world of work have emerged.

This study is aimed at examining when, where, and how calling may intersect with occupational safety. As previously mentioned, this study questions whether the identification of calling may positively correlate with employee safety outcomes. In part, 
this assumption was derived from the fact that calling is motivational construct (Dobrow \& Totsi-Kharas, 2011) and the presence of calling can lead to positive organizational outcomes. That is, people who feel a sense of calling to their work also tend to have an increased energy, endurance, and direction toward tasks that are perceived as fulfilling their calling. Yet, keeping with the current state of the calling literature, this study acknowledges the impact of context on the stated direct relationships. As indicated in the conceptual model (see Figure 1) calling is the independent variable under investigation. This chapter will review the calling construct: its history, definition, and implications, in order to inform this study's purpose.

Calling has a complex history with religious, moral, and philosophical undertones (Hall \& Chandler, 2005). In general, the concept of calling has its roots in Biblical literature and accordingly calling has been commonly associated with Judaism and the early Christian church (Dobrow, 2006). Thus, the concept was not associated with career pursuits or a type of work, but rather, it was a general summons to a relationship with God or the pursuit of work for the greater good. Over the course of time, work was eventually seen as a creative expression reflecting the fulfillment of heavenly directives (Bunderson \& Thompson, 2009). Martin Luther, in particular, made these connections. It was Luther who reestablished the idea that a person is called to serve God by working within the context of his or her own life (Dobrow, 2006).

As a slight departure from the Lutheran view, the Puritan view of work and calling became the first example historically to reflect what would become the $21 \mathrm{st}$ century approach to career choice. Although the secularization of calling was not a stated 
goal of the Puritanical living in a response to the rapidly shifting social and economic structures, the idea of calling would eventually become a malleable concept that could be subjectively founded by each person to align with the mandates of God, the needs of the society, or the desires of the individual. As time progressed, the idea of calling appears to have evolved from a life-summons of God to a pursuit for personal life-meaning justified in part by fulfillment of one's passions. Thus, although, the concept of a calling has religious roots (Elangovan et al., 2010) it has since been expanded to the secular world to better understand the nature and characteristics of deeply meaningful work. In many cases, a sense of calling (without religious underpinnings) has been motivated by various altruistic endeavors such as world peace, environmentalism, diversity education, or public health (Elangovan et al., 2010; Hall \& Chandler, 2005; Steger, Pickering, Shin, \& Dik, 2010). Accordingly, a small but growing number of management scholars have looked to the notion of work as a personal calling (Bellah, Madsen, Sullivan, Swindler, \& Tipton, 1985; Dik \& Duffy, 2009; Dobrow, 2006; Hall \& Chandler, 2005; Kaminsky \& Behrend, 2015; Wrzesniewski et al., 1997) with the assumption that work done solely for economic or career advancement reasons is unlikely to inspire a sense of significance, purpose, or transcendent meaning, yet when work is viewed as one's calling, it assumes both personal and social significance (Pratt \& Ashforth, 2003).

This stream of research straddles much of current western wisdom, which encourages people to follow their passion to find their 'true calling' through their work and career (Bellah et al., 1985). Further, for some time career choice scholars have been examining calling within what Hughes (1958) termed the dual perspective of careers. The 
dual perspective of careers indicates that one's career and the success that comes from having such career is in the eye of the beholder, that is the subjective career, in which the individual evaluates the different facets of their own career whereas, the objective career is one in which the value of one's career is contingent on the view of external society. For example, one's success is defined by tangible outcomes related to having a career (e.g., income, promotions, job mobility; Hall \& Chandler, 2005; Hughes, 1958). Hall and Chandler (2005) argue that one's viewpoint of one's own career is not necessarily one or the other. In fact, due to the changing nature of work (i.e., globalization, rapid technology advances), individuals are increasingly mobile with more career changes and hold greater decision making power in the direction that their career may go. Thus, one's career success is not necessarily contingent on organizational factors, but instead is more due to individual factors, and as such we are more likely to consider our own subjective criteria on what it may mean to be successful. This is not to say that objective career success is not as pertinent. Rather, that subjective career success is also important.

With this in mind, career choice researchers turned their attention to understanding the subjective nature of career success. Calling addresses this more subjective and less rational component of career decision-making by incorporating a sense of meaningfulness and emotional connection to particular careers. In sum, the evolution of the study of calling comes not only due to the changing view of calling within the religious realm, but also in response to the changing nature of work. To better understand the state in which the concept of calling has evolved and the frameworks that 
have emerged from various research studies, the next section reviews the differing definitions of calling.

\section{Calling Defined}

Wrzesniewski et al. (1997) expanded upon the general idea of a sense of purpose in work and the popular idea of callings, as introduced by Bellah et al. (1985), by taking the traditional concept of a career and distinguishing between jobs, careers, and callings. Wrzesniewski et al. (1997) described calling as a focus on the enjoyment of fulfilling and socially useful work. Wrzesniewski et al. contrasts this conceptualization of calling with those who work in jobs and careers and describes those constructs as having primarily extrinsic reasons for performing job duties. Dik, Duffy, and Eldridge (2009) further elaborated on calling, defining it as work that involves an external summons and connection to a sense of purpose in life. This definition of calling consists of three parts: a) transcendent summons originating beyond oneself for a particular type of work, b) the work allows for individuals either to live out a broader life purpose or derive life purpose from the work, and c) the work is "other-oriented" (Dik \& Duffy, 2009). This conceptualization matches much of the transcendental view of calling by viewing calling as stemming from some external source (e.g., destiny, yet not limited to religious beliefs). Thus, this conceptualization adopts a broader secular view and highlights that a calling is more than just a career. Instead, calling is associated with a particular life role. This view suggests that perhaps those that do not experience a sense of calling in their work lives may pursue and experience it in other life activities. It may also be that an individual would realize a call in multiple life roles. The realization of this call, whether it is inside 
or outside of a work environment, provides the individual with a sense of personal stability emanating from a sense of meaning attached to the role (Dik \& Duffy, 2009).

The second definition of calling to be investigated emphasizes calling as an action. According to this definition, the focus of calling is on the course of action itself and not on the intentions of the one who is called, as the first definition may imply. In other words, the process of "how" one arrives at a particular calling receives less the focus. What is important in this definition is that a person's life is dynamic, which implies a need for adaption to the often unforeseen events of life. Therefore, it is implied that calling has either a secular or a religious component and either an occupational or non-occupational component (Elangovan et al., 2010). Additionally, Elangovan et al. (2010) went beyond the basic idea of calling as being other-oriented. They contended that the outward flow of action from the person to the world is shaped by the person's values and beliefs. Again, the nature of a person's values and beliefs are not the focus of this formulation of calling. Similarly, according to the authors, it matters not what the end result of the prosocial action is as long as the intention itself is prosocial. In this estimation, one could pursue and realize a calling that would have damaging repercussions to the world. In this view of calling, the primary emphasis is on selffulfillment and realization of one's own interests and passions rather than the betterment of others. The greater good of society, therefore, becomes an unintended by-product or secondary to the primary motivations (Bunderson \& Thompson, 2009). While this facet may seem contradictory to the notion of altruism, this aspect of calling, according to this definition, expresses the reality that positive intentions do not always produce positive 
results (Elangovan et al., 2010). The final component of the second definition similarly overlaps with the first definition. A calling contains a sense of purpose for the individual. These authors introduced Higgins' (1987) self-discrepancy theory as the underpinning for the realization of a sense of clarity when pursuing a call. According to this theory, the motivation for behavior can be attributed to what one thinks they should do ("ought"), would like to do ("ideal"), and currently do ("actual"). When these discrepancies converge, people will generally experience a sense of meaningfulness as it applies to a particular action (Elangovan et al., 2010).

Although progress has been made, operationally defining the construct of calling remains a challenge for researchers, partly because the construct itself has evolved and has taken on new meaning in recent years (Bunderson \& Thompson, 2009). Even within the last few decades, for example, researchers have defined calling in terms of the following: something performed for its own sake and for personal value or meaning (Bellah et al., 1985), the belief that work helps make the world a better place (Wrzesniewski, 2003), working toward a personal passion (Dobrow, 2006), and work originating from something beyond the self, a transcendental summon (Dik \& Duffy, 2009; Duffy \& Sedlacek, 2007). With all of the possible definitions and considering the evolution of the term from a Judeo-Christian context, it appears that there is still little clarity or consensus across researchers and disciplines regarding the definition. Bunderson and Thompson (2009) argue that although scholars appear to "agree that work viewed as a calling is something deeply personal they seem to disagree about the core" (p. 34). Thus, while this "core" or the underlying mechanism of what produces calling is 
still under debate, scholars consistently agree that calling provides a meaningful view on the experience of work (Wrzesniewski, 2003).

This study takes a broad view of calling and utilizes the definition put forth by Dobrow and Tosti-Kharas' (2011) to define calling as "a consuming, meaningful passion people experience toward a domain" (p. 1003). This definition enables a comprehensive view as to what it means to hold a strong calling. For example, it encompasses the meaningfulness as found in other definitions yet allows for the individual to define how to operationalize that meaningfulness. That is, the individual can determine the benefits that come from pursuit of calling as for the greater good, themselves, their families or any other number of potential benefitting parties. Further, the definition allows calling to be associated with any number of domains and acknowledges that fulfilling one's passion may be central to one's identity as similarly posited by the work orientation literature (Wrzesniewski et al., 1997). As the previous section, indicated although the definition of calling is still in flux, what calling is not has more consensus in the literature.

Distinguishing calling from other constructs. When making a distinction between calling and motivation, one must first consider the fact that pro-social motivation, which is defined by a desire to benefit or help others with one's own actions, has been identified as a key component of calling (Dik \& Duffy, 2009). Both motivation and calling have been classified as a person's orientation toward their goal-directed tasks (Amabile, Hill, Hennessey, \& Tighe, 1994; Davidson \& Caddell, 1994). The underlying assumption of pro-social motivation is the desire to benefit other people. The main characteristic of this type of motivation, similar to most other conceptualizations and definitions, is that it 
includes energy, endurance, and direction for work tasks (i.e., Grant, 2007; Latham \& Pinder, 2005; Thompson \& Bunderson, 2003). Though the fundamental outcomes of persistence, performance, and productivity are similar across various types of motivation, pro-social motivation has unique characteristics. Individuals who are pro-socially motivated feel a sense of moral responsibility, are committed to the people they serve above and beyond the organization, and their desire to perform at a high level is derived from autonomous feelings of work identity and value (Grant, 2008). Although having a calling has only recently begun to include secular work contexts, there is compelling support that individuals who feel called maintain a moralistic view of their work (Elangovan et al., 2010). Yet, as noted above, this moralistic view may encompass more than a view to help the greater good and may include one's own vision of moral responsibility. Drawing upon the qualitative evidence that suggests people with a calling are focused on "doing" rather than "being," another distinction can be inferred between calling and pro-social motivation (Elangovan et al., 2010). Specifically, we can infer that the parameters for someone who is called might be narrower in the sense that just engaging in a job that helps people (e.g., a firefighter or nurse) might not be fulfilling their calling. Additionally, pro-social motivation has been operationally defined to include any behavior that benefits others; however, someone's calling could in fact indirectly benefit people (e.g., an environmentalist who feels called to preserve the rainforest ecosystem). It appears that pro-social motivation has a tendency to ebb and flow in people's lives, but a calling is a more specific and consistent drive toward an ultimate goal. 
Meaningful work is a construct that refers to "work that is both significant and positive in valence"' (Steger, Dik, \& Duffy, 2012, p. 323). Calling is distinct from meaningful work, but they are related, such that calling is typically thought as a piece of the larger construct of meaningful work (Steger et al., 2012). Studies have shown calling to be a distinct construct and some have identified it as an antecedent to work meaningfulness (Duffy, Bott, Allan, Torrey, \& Dik, 2012; Hirschi 2012). Workers can experience work meaningfulness in multiple ways, for example, due to the nature of work itself or job dimensions such as task significance, (Morgeson \& Humphrey, 2006), irrespective of whether they believe their work to be purposeful or not. Job design (Miner, 1984, 2003) examines the impact that occupations have on an individual and is often studied as an antecedent to work meaningfulness.

A highly prominent and influential model within job design, the Job Characteristics Model (JCM) (Grant, Fried, \& Juillerat, 2010; Morgeson \& Humphrey, 2006), argues that occupations impact individuals because it affects their core psychological needs and motivations. The JCM goes on to explicate how job characteristics can satisfy (or dissatisfy) individuals' psychological needs, and the downstream consequences of this on motivation and other work-relevant behaviors (e.g., absenteeism, performance, etc.). Though the JCM speaks to how and why work affects individuals psychologically while at work, the model does not account for how individuals select an occupation. This is the distinguishing factor between calling and job design. Calling dictates a career choice, whereas job design impacts the individual in their occupation of choice. 
Finally, individuals with a strong calling may also display work engagement (Kahn 1990) or have "flow'” experiences (Csikszentmihalyi, 1990). However, researchers generally agree on the long-term nature of calling as opposed to the episodic duration of both work engagement and experience of "flow". Furthermore, intrinsically motivated individuals are drawn toward work from which they derive internal satisfaction, such as enjoyment (Amabile et al., 1994). While researchers contend that individuals who have a calling have a relatively high level of intrinsic motivation (Dik \& Duffy, 2009), individuals may be intrinsically motivated toward a task due to various reasons. For example, the work enables them to develop new skills, or because it is interesting or fun. Thus, although calling overlaps conceptually with a variety of variables, it is distinct and as such can inform various outcomes.

\section{Calling Antecedents and Outcomes}

Very few studies have examined the antecedents of calling. In fact, to my knowledge only two studies have done so. Bott and Duffy (2015) conducted a study with 443 undergraduates across two time periods to find that the search for life meaning and personal growth predicted calling. This finding suggests that those who are actively searching for meaning in their lives and those who are engaging in behaviors and cognitions to support their personal growth were more likely to feel a calling 6 months later. Duffy et al. (2011b) conducted a two-wave longitudinal study on first- and thirdyear medical students to find that over a 2-year period, life meaning and vocational development were found to predict calling. In particular, students who viewed their lives as more meaningful over time and attained greater vocational development also endorsed 
higher levels of calling at the second time point. This is an interesting finding in that it suggests that for medical students, feeling positive about their life and career may put them in a better place to understand and live the career to which they are called. The investigation of calling is still relatively new likely owing to the paltry state of literature on its antecedents. Yet the construct of calling has been theoretically and statistically linked to many constructs related to mental health, well-being, and career-related outcomes (e.g., Bakker, 2015; Dik \& Duffy, 2009; Rawat \& Nadavulakere, 2015; Wrzesniewski \& Dutton, 2001).

Research has found relationships between job performance and satisfaction (e.g., Peterson, Park, Hall, \& Seligman, 2009; Wrzesniewski et al., 1997), work zest (Peterson et al., 2009), decision self-efficacy (Duffy \& Blustein, 2005), career coherence (LipsWiersma, 2002), career commitment (Serow et al., 1992), and overall life satisfaction (e.g., Davidson \& Caddell, 1994; Hall \& Chandler, 2005; Serow, Eaker, \& Ciechalski, 1992; Wrzesniewski et al., 1997). For example, teachers who viewed their work as a calling expressed a desire to teach longer and had a greater appreciation of the positive social components of their careers than those who did not feel a calling (Serow, 1994; Serow et al., 1992). Individuals who view their careers as a calling typically have more career-related meta-competencies, such as self-awareness and adaptability, which enable the individual to make career changes and improvements based on their perceived calling (Hall \& Chandler, 2005). A sample of zookeepers showed that degree of occupational identification, meaning and purpose derived from work, and sense of moral duty varied based on the extent to which they felt called to their work (Bunderson \& Thompson, 
2009). Furthermore, in a recent study (Conway, Clinton, Sturges, \& Budjanovcanin, 2015) found that calling enactment (i.e., the ability to live your calling) on a daily basis relates to daily well-being suggesting that calling can have both daily and long-term effects. These results suggest that working adults more likely to perceive their job as a calling tend to be more committed to their jobs and organizations, feel their work is a strong fit with their personal preferences, experience more well-being, and are more likely to find meaning at work.

Calling is endorsed not only by working adults, but also by college student populations. Duffy and Sedlacek (2007) found that $35 \%$ of their undergraduate sample endorsed the presence of calling in their lives and results demonstrated a positive relationship between life satisfaction and meaning in life. Further, Duffy and Sedlacek (2007) presented significant correlations between calling and career decidedness, choice comfort, self-clarity (self-knowledge), and choice-work salience (importance of future work/career at the time of study). Following up on this study, Douglass and Duffy (2015) found in a sample of undergraduates that calling was correlated to four components of adaptability (i.e., concern, control, curiosity, and confidence) which in turn related to career decision efficacy. In sum, calling has been found to be related to a number of wellbeing and career outcomes across both working adults and college students.

\section{Dark Side of Calling}

Scholars have also discussed the "dark side of a calling", in which having and/or living a calling may relate to negative outcomes for some individuals (e.g., Cardador \& Caza, 2012). Using a sample of aspiring musicians, Dobrow and Tosti-Kharas (2011) 
found that those with a calling were less receptive over time to accept advice from trusted mentors that threatened their sense of calling, pointing to the risk of career foreclosure or "tunnel vision" that may accompany a calling. In their study examining career commitment as a mediator between calling and work outcomes, Duffy, Dik, and colleagues (2011a) found that career commitment actually acted as a suppressor variable in the link between calling and withdrawal intentions; that is, individuals with a calling who were not committed to their career were more likely to have intentions of withdrawing from their current job. The authors argue that it is not just having a calling, but not being able to live out that calling, that could potentially be related to negative outcomes.

Yet even individuals who are currently living their calling may experience downsides. In the extensive qualitative study by Bunderson and Thompson (2009) of zookeepers, participants noted that although they felt that they were living their calling, some felt overworked and at risk of exploitation from their employers. Some participants noted that for intrinsically motivated employees who perform well because they view the work as a calling, employers may not see a need in providing extra incentives or extrinsic reward, resulting in such employees being passed over for pay raises. Similarly, such employees may be asked to do more difficult or unpleasant jobs than other employees due to their willingness to readily comply with such requests. Another vulnerability of a calling is workaholism, or an over-identification with work resulting in difficulty maintaining work and nonwork balance (Cardador \& Caza, 2012). 
Workaholics can be defined as people who identify themselves as workaholics, are identified by others as workaholics, and have lower life satisfaction and higher worklife imbalance than they want (Spence \& Robbins, 1992). The term workaholic is generally viewed as a negative word, and the word is associated with addiction. It can be or lead to a dysfunctional behavior, and dysfunctional behaviors are negative for organizations (Porter, 1996). It does seem possible however, for an employee with a calling to be a workaholic. In a study by Van Beek, Taris, and Schaufeli (2011) found that it was possible for an engaged employee to be a workaholic. Van Beek et al., distinguished the resultant identities as workaholic employees, engaged employees, engaged workaholics, and nonworkaholics. The benefit of being an engaged workaholic versus simply a workaholic is that engaged workaholics do not suffer the same amount of burnout, suggesting that engagement may serve as a buffer for reducing burnout (Van Beek et al., 2011). This same case may also exist for an employee with a high calling orientation indicating that calling and workaholism are distinct concepts and as such calling may serve to reduce the impact of workaholism. Further, whereas, workaholics are driven by controlled (extrinsic) motivations, employees with a calling are driven by autonomous (intrinsic) motivations.

As stated throughout, the relationship between calling and safety has yet to be investigated and as such, the "dark side" of calling could impact safety. It appears that when one feels called to their occupation they are more willing to work hard for it and put more pressure on themselves and their organization (Vinje \& Mittelmark, 2007). Could the attainment of one's own goal undermine an employee's safety behaviors? 
While this possibility has yet to be tested elsewhere, there is tangential literature to suggest a positive relationship between calling and safety. For example, in their metaanalysis, Nahrgang et al., 2011 found consistent with the JD-R model that job resources such as knowledge, autonomy, and a supportive environment were motivating employees toward higher engagement and that engagement motivated employees toward working safely. While, as stated above, engagement and calling are different constructs they share similarities. Citing this along with the bulk of the calling literature showing positive organizational outcomes, and using the norm of reciprocity, I argue that employees who see their organization as the vehicle for living their calling will reciprocate with safe behaviors.

In sum, despite the evidence that having a calling relates to positive outcomes, evidence also points to a dark side of calling for individuals who foreclose too early on their career choices, work in jobs that are not their calling, become too invested in their work, or get exploited by their employers. However, the limited research on this topic makes any conclusions suggestive rather than definitive. The calling literature has concluded that these negative consequences may be due to certain contextual variables yet to be explored. Consequently, I have attempted to fill this gap by exploring two moderators. 
Chapter 3

Potential Moderators of the Relationship Between Calling and Safety

As noted earlier, one specific purpose of this study is to investigate potential moderating factors in the relationship between calling and the safety outcomes. Also, as previously outlined, the two moderating variables were selected due to the context in which this study takes place. When reflecting on the initial meetings with the USFS along with the pilot work results, workload and supervisor support were two of the most cited stressors and/or resources within the USFS. The purpose of this chapter is to give a brief overview of both workload and supervisor support (see Figure 1 for a visual representation). A deeper discussion is outlined in Chapter 5 and 6 as I build the arguments for this study.

\section{Workload}

Bowling and Kirkendall (2012) define workload as "an all-encompassing term that includes any variable reflecting the amount or difficulty of one's work" (p. 222). As such, workload includes both quantitative and qualitative dimensions (Parasuraman \& Purohit, 2000), as well as both mental and physical sub-dimensions (Janssen, Bakker, \& de Jonge, 2001), and it can be assessed as either a subjective perception or as an objective characteristic of one's work (Ganster, Fox, \& Dwyer, 2001; Spector \& Jex, 1998).

Generally, relationships between workload and its outcomes are expected to be negative. As workload increases to the point of overload, detrimental effects on psychological and physical health as well as performance and effort should be observed. Support for this relationship at the individual level of analysis can be drawn from 
research by Kawada and Otsuka (2011) and Sutton and Rafaeli (1987) who found individual-level overload to be negatively related to worker job satisfaction. Additionally, multiple studies have demonstrated that employees with greater workload demands report greater burnout, especially emotional exhaustion (e.g., Friedman, 2002; Posig \& Kickul, 2003) and lower psychological (e.g., anxiety and depression; Daniels \& Guppy, 1997) and physical health (e.g., Daniels \& Guppy, 1997; Spector \& Jex, 1998). Furthermore, using a within-person design, Ilies, Dimotakis, and Pater (2010) found that daily workload was related to affective distress and blood pressure.

In addition to being linked with employee well-being, workload is also expected to have implications for organizational well-being although the research is conflicting. For example, workload has been found to be positively related to performance (Spector \& Jex, 1998), yet other studies have found a negative relationship (Fritz \& Sonnentag, 2006) indicating potential moderators may exist. Similarly, although it makes theoretical sense for workload to correlate negatively with Organizational Citizenship Behaviors (OCBs) (i.e., voluntary helping behaviors that are not specified by the employee's job description), in that as workload increases these voluntary behaviors decrease there are studies to suggest otherwise. Miles, Borman, Spector, and Fox (2002) found a positive correlation of .31 between workload and OCBs. It has been suggested that this positive relationship is due to the employees' willingness to engage in OCBs that in turn allows their work to "pile-up" (Miles et al., 2002). The literature is less inconsistent when looking at counterproductive work behavior (CWB) (i.e., voluntary actions that employees engage in for purpose of harming their organization or one within it). Keeping 
with the theorizing of this study, workload can indicate to employees that their organization does not care for their well-being which creates a break in the social exchange relationship thus causing the employee to "reciprocate" (Goulder, 1960) with CWBs. Research has found support for the positive relationship between workload and CWBs (Chen \& Spector, 1991; Miles et al., 2002). Workload has also been found to be related positively to absenteeism (Unruh, Joseph, \& Strikland, 2007), and presenteeism (Biron, Brun, Ivers, \& Copper, 2006). Finally, Bowling, Alarcon, Bragg, and Hartman (2015) summarized the existing literature using meta-analytic procedures. The authors find support for their hypothesis that workload relates positively to work stressors and in particular, role ambiguity, role conflict, work-to-family conflict, and family-to-work conflict. Workload was also found to be significantly related in the expected directions with job satisfaction, mental well-being, strain, depression, distress, fatigue, emotional exhaustion, depersonalization, personal accomplishment, global health, and physical symptoms. Finally, in conjunction with this study, the meta-analytic results showed that general social support $(\rho=-.20)$, social support provided by one's supervisor $(\rho=-.20)$, and social support provided by one's co-workers $(\rho=-.11)$ were each negatively related to workload.

Workload and safety. As noted by Bowling and Kirkendall (2012) workload is relatively under-examined in the occupational stress literature as most studies tend to encompass workload as part of a host of other "stressful working conditions" (p. 221). As such, few studies have examined workload and its direct link with safety. Although exceptions do exist; Frone (1998) found that excessive workloads were related to 
workplace injuries in a sample of employed adolescents. Iverson and Erwin (1997) found that workload related to occupational injuries in a sample of blue-collar manufacturing employees. In looking at a related construct, work pressure, several studies have found that increased work pressure is related to injuries (Barling, Kelloway, \& Iverson, 2003; Zohar, 2002) safety participation (Brown, Willis, \& Prussia, 2000), accidents and safety compliance (Clarke 2006; Goldenhar, Williams, \& Swanson, 2003), and safety performance, (DeJoy, Schaffer, Wilson, Vandenberg, \& Butts 2004).

Many studies that examine safety and single out workload as a variable of interest tend to be conducted in very specific industries. For example, in reviewing the literature on the workload of Intensive Care Unit Nurses, Carayon and Gurses (2005) found that nursing workload is one of the most important determinants of patient safety and quality of care in ICUs. In fact, as reported, $81 \%$ of incidents of compromised quality of care (i.e., drug administration or documentation problems, inadequate patient supervision, incorrect ventilator or equipment setup) came from inappropriate staffing and these in turn led to undesirable patient outcomes including major physiological change, patient or relative dissatisfaction, and physical injury. In another study with nurses, Holden et al. (2011) found that nursing workload was related to medication error likelihood. In sum, in looking at the bulk of the research on safety and workload, we can conclude that as workload goes up so does the probability of unsafe behavior and/or outcomes. On the other hand, turning to the other moderator under investigation, the opposite relationship appears to be true.

\section{Supervisor Support}


Supervisors may provide support either by the presence of supportive behaviors (e.g., provide information, instrumental aid, mentoring) or by the absence of nonsupportive behaviors. There are three broad types of social support identified in the literature - tangible, informational, and emotional (Cohen, Mermelstein, Kamarck, \& Hoberman, 1985; House, 1981). Tangible support, also called instrumental support, involves assistance in terms of resources, time, and labor. Informational support involves an individual providing support in the form of information needed to manage demands or problems. The third broad type of support is emotional support. This refers to the perception that the support giver cares and is concerned about the recipient. Emotional support can be provided verbally (e.g., questioning about employee well-being) or the supervisor can make it clear by simply being available and listening to an employee that wants to talk through a specific problem.

As agents of the organization, supervisors communicate the organization's goals and values to subordinates and evaluate employee performance. Subordinates' organizational rewards (merit pay, skill training) and working conditions (greater autonomy, recognition from upper-level management) are contingent upon supervisor appraisals. Supervisor support helps employees to cultivate positive attitudes toward their organization because supervisors act as agents of the organization (Levinson, 1965). Employees tend to view their supervisors' orientation toward them as the expression of perceived organizational support (Rhoades \& Eisenberger, 2002). A study conducted by Eisenberger, Armeli, Rexwinkel, Lynch, and Rhoades (2001) reported that supervisor support is a predictor of perceived organizational support. This might be because 
supervisors who seem to be honored by the organization would be assumed by employees to strongly represent the organization's image (Eisenberger et al., 2001). When individuals receive socio-emotional resources from their organization, they feel obliged to repay the organization (Cropanzano \& Mitchell, 2005). That is, when trust, obligations, socio-emotional resources, and a long-term orientation characterize the relationship between the supervisor and the employee, the employees should perceive this as an exchange relationship. Thus employees who experience good treatment by their organization are likely to "give back" with more favorable attitudes toward their employer (Meyer \& Allen, 1991). Studies signify the positive impact of supervisory support on organizational commitment, job satisfaction and employees' intent to leave the organization (Muhammad \& Hamdy, 2005).

Demographic variables such as similarity in race and gender (Hopkins, 2002; Varma \& Stroh, 2001), and family values (Thompson, Brough, \& Schmidt, 2006) of the supervisor and subordinate have been studied as antecedents of supervisor support. Furthermore, there are studies that have examined the situational influences in the workplace on supervisor support (Green, Anderson, \& Shivers, 1996; Kinicki \& Vechhio, 1994). Related to the current study, Green et al. (1996) studied the relationship between demographic and organizational variables and supervisor support (i.e., supervisor support as measured as Leader-Member Exchange) among 208 employees working in 31 libraries and reported a negative relationship between workload and supervisor support. It was further suggested that organizational contexts that increase the discretion of the supervisor may facilitate greater supervisor supportiveness. 
Supervisor support and safety. Supervisor support for safety represents the extent to which supervisors encourage safe working practices among their subordinates. Empirical evidence has demonstrated that supervisor support facilitates occupational health and safety practices (Cohen, Smith, \& Anger, 1979; Lim, 1997) and perceived safety (Janssens, Brett, \& Smith, 1995). Further, Nahrgang, Morgeson, and Hofmann (2011) found that a supportive environment was the most consistent predictor of safety outcomes such as unsafe behavior, and accidents and injuries (negative relationship), and Li, Jiang, Yao, and Li (2013) found that supervisor and coworker support could affect safety compliance (positive relationship). Additionally, Torp and Grogaard (2009) conducted a multilevel study showing that at the worker level, health and safety compliance correlated with social support and management support. At the group level, management support correlated significantly with high worker compliance with health and safety routines. These studies provide evidence that having a supportive supervisor can be beneficial for an employee's safety performance. Hofmann and Morgeson (1999) also demonstrated that while perceived organizational support was related to improved safety communication, the perceived relationship with one's supervisor was shown to be related to high levels of safety communication and safety commitment as well as lower frequencies of injuries. Their results imply that supervisor support has effects that exceed perceived organizational support, which related only to improved safety communication. Through providing information to subordinates or sharing their attitudes or opinions regarding safety, supervisors often act as a driving force affecting the safety of the workplace (Hofmann \& Morgeson, 1999; Leiter \& Harvie, 1997). Evidence also exists 
that supervisory values about safety affect subordinates' internalization of similar values, which may extend to actual behavioral modeling of safe work practices (Maierhofer, Griffin, \& Sheehan, 2000). Finally, supervisory safety practices have been related to an increase in subordinate compliance with safety procedures as well as a decrease in subordinate accident rates (Hayes, Perandan, Smecko, \& Trask, 1998).

\section{Supervisor Support and Workload in the USFS}

In the early 2000s, Region 6 experienced significant downsizing, which reduced its staff significantly. Each Forest switched to a "Zone Program," pairing two or more Districts under one overarching supervision structure. As one worker noted, "This program is good for budgetary reasons, but has significant drawbacks in terms of workload and supervisor oversight and contact." Although the supervisors technically manage two Districts, they are often housed in only one; thus, crewmembers situated in their home office receive a great deal of daily oversight, while the off-site workers receive little to no contact or support. This situation was reported with remorse from both non-supervisory and supervisory participants. One District Ranger noted that he spends a significant amount of his time traveling to check-in with his employees, "I try to check in with all my employees weekly, it causes a lot of extra travel time and work, but it is worth it, they need to see me, know I care." Natural Resource and Recreation supervisors and non-supervisory workers are funded through a combination of program- and projectlevel dollars, while their seasonal employees are paid primarily through project-level funds, unless they make themselves available for firework, which is funded exclusively at the program-level. Outside of fire, budgeting for seasonal employees is written into grant 
applications. Non-fire, non-supervisory workers who do not perform project lead duties are not required to attend any meetings and often only check in with their supervisors on an as-needed basis and primarily via email. Throughout the pilot work, these 'lone workers' noted strains associated with their lack of supervisor support and oversight.

The pilot work highlighted a number of stressors for USFS employees associated with workload, understaffing, and disparate work roles and expectations. Participants at every level indicated that their workload was a significant stressor. One supervisory-level participant detailed the tasks they wanted to accomplish, noting that they were always coming up short and disappointing their subordinates, leaders, and co-workers. Another indicated that the culture was one of "do more with less." Some supervisors acknowledged the heavy workloads faced by employees and tried to find ways to manage priorities and integrate work-life balance effectively, but were also struggling with their own workloads. In many cases, non-fire workers were the only ones performing their specific jobs. This led to an increased sense of responsibility in ensuring task completion, as "there is no one else who can take this on." Work overload and perceived lack of taskmanagement support were often related to negative work attitudes, increased work hours, and/or "work nightmares."

In conclusion, this chapter sets the stage for the relationships under investigation in this study. This chapter gives a brief overview of the literature as well as a definition of each of these key constructs. In the next chapter, I will examine the outcome variables in this study; safety motivation and safety compliance. 


\section{Chapter 4}

\section{Safety Motivation and Safety Compliance}

Given the high cost of occupational accidents and injuries, and the efforts by organizations to reduce these costs, many safety researchers logically focus on the reduction of accidents and injuries (Clarke, 2006). However, focusing on accidents and injuries can present problems as outcome measures for researchers investigating organizational influences on occupational safety. First, accidents and injuries occur infrequently and are not normally distributed, making statistical prediction difficult. Second, accidents and injuries are considered a lagging indicator of the state of safety as they only occur when there is a system failure, and do not provide any information on safety conditions across worksites or risks to workers (Seo, Torabi, Blair, \& Ellis, 2004). Consequentially, a number of researchers tend to evaluate safety performance as a key indicator of workplace safety opposed to evaluating accidents and injuries. Safety performance refers to the actions or behaviors that employees carry out to support their own safety as well as that of their coworkers and is typically described in terms of safety compliance and safety participation (Burke \& Signal, 2010). These dimensions are based on Borman and Motowidlo's (1993) distinction between task and contextual job performance dimensions, where the former is a formally mandated component of an employee's job and the latter constitutes informal extra-role behaviors (Neal, Griffin, \& Hart, 2000). According to Griffin and Neal (2000), safety compliance is defined as the "core safety activities that need to be carried out by individuals to maintain workplace safety" (p. 348), whereas safety participation refers to "behaviors such as participating in 
voluntary safety activities or attending safety meeting" (p. 348). Thus, whereas compliance directly contributes to workplace safety (e.g., wearing personal protective equipment), participation indirectly contributes to it by creating a safety-supportive environment (e.g., attending safety meetings; Griffin \& Neal, 2000). Employees who exhibit safety compliance and participation are less likely to have accidents and injuries at work because they are following safety rules and procedures (compliance) and taking proactive measures to address potential risks (participation; Jiang, $\mathrm{Yu}, \mathrm{Li}, \& \mathrm{Li}, 2010$ ). This framework has received support in various studies examining workplace safety (Inness et al., 2010; Neal \& Griffin, 2006). Christian and colleagues (2009) emphasized the importance of distinguishing safety-related behaviors from their outcomes. For one, they are conceptually different in that safety performance behaviors are intangible, whereas "safety outcomes are tangible events or results, such as accidents, injuries, or fatalities" (p. 1104). Furthermore, the relationships that other constructs have with safety performance and with safety outcomes are different; in fact, safety performance is frequently identified as a direct antecedent of safety outcomes (e.g., Neal \& Griffin, 2004). Thus, it is important to distinguish between them in empirical research.

\section{Safety Performance}

The literature proposes several antecedents to safety performance in general and to safety compliance in particular. One of the more studied antecedents is safety climate. Safety climate is described as a perception (can be individual or shared by a group) of the "policies, procedures, and practices relating to safety in the workplace" (Neal \& Griffin, 2006, pp. 946-947). Neal and Griffin (2006) use social exchange theory to argue that 
when employees believe the organization cares about their well-being, they will develop a sense of obligation to respond by exhibiting behavior that will benefit the organization. Because organizations with a strong safety climate have invested time, energy, and resources into keeping employees safe, employees are likely to believe that the organization cares about their well-being. As a result, employees reciprocate the concern by following established safety protocols. In a meta-analysis, Clarke (2006) looked at safety climate as an important predictor of safety performance, and accidents/injuries. Clarke (2006) hypothesized safety performance would moderate the relationship between safety climate and accidents/injuries. While safety climate was related to both the participation and compliance aspects of safety performance, the relationship between safety performance and accidents and injuries was not well supported. The relationship was found to be moderated by research design.

Christian et al. (2009) also looked at multiple predictors of safety performance in a meta-analysis of 90 studies. Predictors were categorized as either distal or proximal and situation-related or person related. They hypothesized distal situation-related factors (safety climate and work pressure) and distal person-related factors (personality characteristics and job attitudes) would predict proximal person-related factors (safety motivation and safety knowledge), which would relate to safety performance (compliance and participation), which, in the end, would predict safety outcomes (accidents and injuries). Predictions were generally supported. Weak to moderate correlations between distal person- and situation-related factors and safety performance were found with one of these being that of work pressure and safety compliance which is relevant for the 
current study. Safety knowledge and safety motivation were the best predictors of safety performance. Group-level safety climate, defined as shared perceptions of work environment characteristics as they pertain to safety matters that affect a group of individuals, was found to be the strongest predictor of accidents and injuries. The researchers concluded that their original hypothesis was supported based on the support for their exemplar model and pattern of meta-analytic correlations.

In another meta-analysis, Clarke and Robertson (2005) looked at the relationship between the big five personality traits and accidents (i.e., not safety performance). The researchers looked at both occupational and non-occupational accidents, such as car accidents. The findings indicated the relationship between personality traits and accidents was moderated by accident type. Further analysis showed low agreeableness and high neuroticism were related to occupational accidents, while extraversion, low agreeableness, and low conscientiousness proved to be significant predictors of car accidents.

One of the more recent and largest meta-analyses related to safety was conducted by Nahrgang et al. (2011). Using 203 independent samples the researchers looked at how job demands and job resources relate to workplace safety through health impairment and motivational processes. Overall, they found general support for their model. Job demands were found to impair health, were related positively to burnout and were negatively related to engagement. The opposite was true for job resources, which showed a positive relationship with employee engagement and a negative relationship with burnout. Furthermore, the research showed burnout was negatively related to working safely, 
while employee engagement was positively related to working safely. The job demands category consisted of risks and hazards, physical demands, and complexity. The job resources category included knowledge, autonomy, and a supportive environment (i.e., social support, leadership, and safety climate). The researchers hypothesized that both burnout and employee engagement would mediate the relationship between job demands/resources and safety outcomes. Results suggest burnout and engagement partially mediated the relationship between job demands/resources and safety behaviors. Nahrgang et al. (2011) included four different types of industries in their meta-analysis: construction, healthcare, manufacturing/processing, and transportation. Risks and hazards was the most consistent job demand in explaining variance in burnout, engagement, and safety outcomes. However, the specific job demand that accounted for the most variance did differ across industries. A supportive environment was the job resource that consistently explained the most variance in burnout, engagement, and safety outcomes. This did not vary across industries.

Neal and Griffin (2002) proposed a summary of the relationships among antecedents, determinants, and components of safety performance. This summary includes leadership, conscientiousness, and safety climate as antecedents; motivation, knowledge, and skill as determinants; and safety compliance and participation as components of safety. It is clear that the research has focused more on some aspects of Neal and Griffin's (2002) model than others. For instance, there is a great deal of focus placed on the importance of safety climate, and less on leadership, conscientiousness, or other possible antecedents. Nahrgang et al. (2011) looked at leadership as part of the 
supportive environment job resource. The outcomes traditionally linked to safety performance are explained below.

Safety performance is commonly included in safety-related models as an antecedent of safety outcomes such as accidents, near misses, and injuries. Accidents are unintentional and undesirable occurrences which are frequently triggered by human errors or lapses on the part of the worker (Neal \& Griffin, 2006), and are said to be preceded by complex employee-environment interactions (Janicak, 1998). Near misses, on the other hand, are incidents that could have resulted in an injury but did not (Goldenhar et al., 2003). Near-misses can be conceptualized as warnings, as minor incidents in the past are said to be the foundation for subsequent ones. Furthermore, nearmisses may only differ from actual injury-causing accidents due to chance or because a final trigger event is missing (Vrendenburgh, 2002). The inclusion of safety performance in safety-related research is beneficial, because it is a measurable criterion that has a closer relationship to psychological factors than safety outcomes (Christian et al., 2009). Accordingly, the direct prediction of safety performance as opposed to accidents and injuries is more precise, especially since, as noted above, accidents are by nature lowfrequency occurrences and typically have skewed distributions (Neal \& Griffin, 2006; Zohar, 2000). In support of this theory, safety performance as measured by safety participation and compliance has been consistently and directly linked to safety outcomes such as accidents and injuries (e.g., Clarke, 2006; Jiang et al., 2010; Probst \& Brubaker, 2001). Safety performance is frequently examined as a mediator, linking safety outcomes to constructs such as safety motivation (Probst \& Brubaker, 2001). 


\section{Safety Motivation}

Empirical findings have consistently demonstrated the relationship between safety motivation and safety performance. Griffin and Neal (2000) considered the relationship between components of safety performance (compliance and participation) and two dimensions of safety motivation: motivation to perform safety related tasks (compliance; sample item: "It is important to consistently use the correct personal protective equipment"), and motivation to take part in activities that support safety in the organization (participation; sample item: "I believe that it is important to promote our safety program”). Compliance motivation was moderately correlated with both safety compliance $(\mathrm{r}=.32)$ and safety participation $(\mathrm{r}=.26)$. Participation motivation was moderately correlated with both safety compliance $(r=.29)$ and safety participation $(r=$ .53). Taken together, these findings suggest that individuals who report a high willingness to perform job duties safely are more likely to report behaving safely on the job. Christian et al. (2009) supported this notion in a meta- analysis, where overall safety motivation was found to be strongly associated with overall safety performance (mean $r=$ .57). Vinodokumar and Bhasi (2010) demonstrated a positive relationship between safety motivation and safety compliance $(\mathrm{r}=.39)$ and participation $(\mathrm{r}=.43)$ behaviors. Similarly, Buck (2008) reported safety motivation was positively associated with safety compliance $(\mathrm{r}=.51)$ and participation $(\mathrm{r}=.47)$. Longitudinal investigations have provided evidence to suggest that, over time, individuals high on safety motivation may demonstrate positive changes in safety performance. Probst and Brubaker (2001) found that safety motivation had a lagged effect on safety compliance 6 months later. It is 
important to note that safety motivation in this case was defined extrinsically as "the employee's degree of incentive to adhere to their organizations safety regulations" ( $p$. 140; Probst \& Brubaker, 2001). Lagged effects were also reported by Neal and Griffin (2006), who measured safety motivation and safety performance at two time points, over a period of four years. Individual safety motivation at Time 1 was associated with positive changes in individual safety participation in Time 2 . However, there was no observed effect of Time 1 motivation on safety compliance at Time 2 . Thus, employees who are motivated to act safely are more likely to engage in activities that contribute to overall workplace safety. However, over time, this willingness does not change the likelihood that employees will comply with safety rules and procedures. Unlike the consistent relationships demonstrated between safety motivation and safety performance, evidence of a relationship between safety motivation and safety outcomes has been mixed. Some evidence suggests that individuals who value safety and are motivated to put forth effort to act safely are less likely to be involved in accidents. For example, Newnam, Griffin and Mason (2008) reported individual safety motivation was negatively associated with work-related motor vehicle accidents, such that workers who were more willing to follow driving rules and regulations were less likely to be involved in an accident. Other researchers have failed to find a relationship between safety motivation and objective safety indicators (i.e., injuries requiring first aid and near misses; Zacharatos, Barling, \& Iverson, 2005). These results can be taken to suggest that because motivation is a determinant of behavior, relationships with objective measures of performance are likely to be indirect, mediated by safety performance. Further, these 
findings explain why the majority of researchers have considered safety performance as a mediator between predictors of safety performance (i.e., antecedents and determinants) and objective outcomes. Using safety motivation as a mediator in a recent meta-analysis, Christian et al. (2009) reported that the indirect effect of safety motivation on accidents and injuries was -.16 , while the direct effect of safety performance on accidents and injuries was -.31 . These results suggest safety motivation leads to effective safety performance, which in turn, reduces the risk of accidents and injuries.

In this chapter, I gave a brief overview of the safety performance and its antecedents and outcomes. In the next chapter, I provide a more in depth view of the theoretical frameworks behind this study's hypotheses. 


\section{Chapter 5}

Theory

In the previous chapters I have reviewed literature surrounding my main hypotheses. I reviewed the constructs of calling, the two moderators (i.e., workload and supervisor support) and the two outcomes (i.e., safety motivation and safety compliance). In this chapter, I will detail the theoretical framework used to support the hypotheses within this study. Specially, I will outline two overarching theories to introduce this study's hypotheses, Social Exchange Theory (SET) and the Job Demands and Resources Model (JD-R).

\section{Social Exchange Theory}

Social exchange has been defined as "actions contingent on the rewarding reactions of others, which over time provide for mutually and rewarding transactions and relationships" (Cropanzano \& Mitchell, 2005). Social exchange relationships tend to involve socioemotional resources, such as commitment, support, or trust (e.g., Konovsky \& Pugh, 1994; Lavelle, Rupp, \& Brockner, 2007). Therefore, these relationships tend to develop over a period of time (Rupp \& Cropanzano, 2002). This can be contrasted with economic exchange, which is characterized as more short-term, with quid pro quo exchanges (Blau, 1964). SET has been credited for connecting individuals' behavior in the workplace to job outcomes, based on the types of exchanges that occur within employee-organization relationships (Shore, Coyle-Shapiro, Chen, \& Tetrick, 2009). Additionally, the way social exchanges are allocated throughout the organization has the potential to significantly impact the quality of the relationships. One factor that 
contributes to how individuals identify the quality of their relationship depends on what forms of socioemotional resources are being shared in social exchanges (Shore et al., 2009). The socioemotional resources shared in the partnership are often dictated by the degree of value congruence presented between employees and the organization (Shore et al., 2009, p. 290). Thus, by extension, values that have been associated with being an essential part of an organization's culture can impact a number of individual outcomes (Posner, 2010). That is, when individuals' personal and organization values were congruent with one another, positive work behaviors and organizational outcomes were the product of those shared value systems (Posner, 2010).

Furthermore, the social exchanges between employees and organizational leaders are voluntary actions that are acted upon on the basis that there will be some form of reciprocation from the other (Jepsen \& Rodwell, 2010). Work attitudes and behaviors of employees have been found to follow along the perception that the employees believe that the organization values them. According to Eisenberger, Huntington, Hutchison, \& Sowa (1986), when employees perceived that organizations treated them equitably because of invested shared values, employees demonstrated positive work attitudes and behaviors. In fact, shared values among individuals make social exchanges and opportunities for reciprocation easier because of the established trust, which allows for increased cooperation to exist (Zhang, Wan, Jia, \& Gu, 2009). Further, according to SET, the more shared values are presented between partners, the stronger the foundation is for exchanges to occur, leading to a higher quality of reciprocal behavior and resulting in improved work outcomes (Zhang et al., 2009). Further, linking this to calling, there is 
research showing a strong link between calling and commitment to one's current, or future, career (e.g., Bunderson \& Thompson, 2009; Duffy \& Sedlacek, 2007; Serow, 1994; Steger et al., 2010). That is, those more likely to view their career as a calling report higher levels of commitment to that career and by extension that role. The calling research also acknowledges that a higher calling orientation creates a higher identification to one's role but this may not necessarily translate to the organization. That is, while one may identify with a role it is not inherently true that one will identify with their organization.

Organizational identification occurs when individuals perceive their organization to be self-defining or a central component of their self-concept (Pratt, 1998). To identify, the individual needs to see him/herself as psychologically intertwined with the fate of the organization (Ashforth \& Mael, 1989; Mael \& Ashforth, 1995). When organizations offer individuals a wide spectrum of resources, such as monetary, interpersonal and symbolic, they spur the feeling of a relationship between the self and the employer, and contribute to identification with the organization (Rousseau 1998). Furthermore, Rousseau (1998) notes that helping the organization to achieve success can also contribute towards making a person feel more successful. This identity with the organization concerns the extent to which individuals appreciate the values of the organization for which they work and this identification can provide individuals with an experience of positive self-worth, which may motivate the deployment of efforts that benefit the organization (Joshi \& Randall 2001). This identification process then becomes an exchange between the organization and the employee, in which the organization provides resources and the employee then 
identifies with the goals and values of the organization. In the case of this study, I will argue that one with high calling is inherently invested in their work role and sees the organization as one that will help them accomplish their goals. That is, those with higher calling toward their careers will invest in the exchange relationship because they perceive it as most useful for achieving their desired outcome through the alignment of personal and organizational goals.

Thus far, I have argued that those that report higher calling are invested in their work role and further, they will see the organization as the impetus to reaching their goals. There is little work on calling and the pursuit of goals but in a study of diverse adults/employees recruited via MTurk and social media, Allan and Duffy (2014) use selfconcordance theory to argue that it is the pursuit of personal goals that links calling with life satisfaction. In particular, the authors examined career self-efficacy goals as the mediating factor. Yet, unless the employee's goal is to maximize safety (and it could be) it is not inherently clear that a higher calling orientation will lead to safety. Thus, it is not only the alignment of values and goals between the organization and the employee that increases employee desired behaviors, but it is the exchange relationship that dictates that the employee will reciprocate with increased safety.

Bringing this line of thinking all together, I have posited that those who report higher calling will identify with their work role and by extension their organization through the development of a social exchange relationship. This social exchange relationship allows for the alignment of values and goals and, further, through the norm of reciprocity the employee is likely to espouse organizational goals and behave in ways 
that benefit the organization.

I will also call upon SET and by extension Psychological Contract Theory (PCT) to explain why workload may impact the proposed positive relationship between calling and safety. The term psychological contract has been recognized as a contemporary framework that helps to operationalize how social exchange and the norm of reciprocity affect employees' attitudes and behaviors (Shore et al., 1994). For instance, when employees perceive their employer as having upheld his or her end of a reciprocal exchange agreement (e.g., providing employee development, merit raises, etc.), employees feel obligated to reciprocate the gesture by increasing their efforts to fulfill the organization's objectives. The willingness of employees to return the gesture to their employer aligns with Blau's (1964) norm of reciprocity theory, which proposes that there should be a sense of obligation to return the benefits to those from whom one has benefited. In short, the norm of reciprocity by default creates a psychological contract between employees and their employer that encourages a reciprocating exchange of economic and socioemotional resources (Robinson, 1996; Robinson \& Rousseau, 1994).

More explicitly, PCT maintains that employees form beliefs that there are mutual obligations between themselves and their employers. These beliefs constitute their psychological contracts (Rousseau, 1995). Further, the contributions and rewards exchanged in a psychological contract (i.e., the currency) are characterized as either economic or socioemotional (Rousseau, 1995).

Thompson and Bunderson (2003) built upon these "currencies" to suggest that another currency is also being exchanged; that of an "ideological currency," or in other 
words the ideological objectives of the employee and the organization. In reading Blau's original propositions, Thompson and Bunderson argue that these ideological rewards are missing in the current state of the social exchange and psychological contract literatures. Furthermore, the authors argue that "employee perceptions about the organization's obligations are not grounded solely in personal entitlements but also in the promotion of a cause they highly value" (p. 571). The exchange of ideological rewards is one that is highly relevant in those that feel called to their occupations. Inherent in calling is the notion that one is fulfilling some greater cause. This cause may be for a greater good or for the individual, but it indicates that there is some sort impetus to the pursuit of that career. In fact, Blau defines the ideological rewards as those that come from the pursuit of a cause. In sum, when examining the potential "currencies" to be exchanged in an exchange relationship, one that is often overlooked is the ideological currency. Further, it is this currency that may be most salient to those with high calling.

So, what occurs when a breach to the ideological contract occurs? Researchers have suggested that different currencies are associated with different responses to the perception that the contract has been breached or violated (Rousseau \& McLean Parks, 1993). Thompson and Bunderson argue that in ideology-infused contracts a breach may have added importance because the organization becomes an embodiment of what the individual stands for or values. This breach may undermine the perception of an employee's work as contributing to a worthwhile objective. Further, because as I have argued above that the individual whom reports a high calling will identify with their organization, a breach to this contract may come with heavier consequences than for one 
with low calling. This study attempts to understand what occurs when someone with high calling is under conditions of high workload. In and of itself, workload may not be an intuitive vehicle in which to investigate a breach of contract but I argue in the context of this study, it is highly relevant.

As mentioned previously, workload was selected as a moderating variable because of the prevalence of high workloads for those in the USFS. This prevalence is not without concern and priority for top leadership, but is due to budgetary constraints that are often outside of the control of the leader. In one of our first meetings with top leadership, it was mentioned that supervisors recognized that a reduction in workforce created undue burden on employees and thus had lowered performance exceptions in attempt to help employees manage their workloads. Yet, when talking with employees the lowered performance expectations were not seen as beneficial. In fact, several employees were trying to maintain their own standards of job performance even under conditions of high workloads. I would argue that those employees that report a high calling (and by extension a high occupational identity) may be more likely to hold to these higher performance expectations even under such constraints. Furthermore, by lowering the performance standards the organization may have implicitly signaled to employees that their work is of little value. Thus, the lowered performance standards may have been seen as a breach to the ideological contact such that by lowering performance standards the organization signaled to employees that the work being conducted within this region of the USFS is of lessor value. Finally, the workload itself is such a demand on employees that this too is seen as a breach to the contract between the employee and 
the organization. Just as SET can justify the hypotheses under investigation, so can the JD-R.

\section{Job Demands and Resources Model}

By using SET to argue that as calling went up so did the safety outcomes, inherent is the assumption that those with low calling will report lower safety motivation and compliance. The JD-R allows me to shift my focus away from why high levels of calling foster safety and toward the question of what can be done to cultivate safety among those with low levels of calling. I propose that supervisor support, which in this study is framed within the JD-R as a resource, can mitigate the impact of low calling on safety.

The JD-R model (Bakker \& Demerouti, 2007; Demerouti, Bakker, Nachreiner, \& Schaufeli, 2001) was developed to integrate and elaborate upon previously developed job characteristics models such as the Demand Control Model (Karasek, 1979) and the Effort Reward Imbalance Model (Siegrist, 1996). First, whereas most other job characteristics models had emphasized health impairing job characteristics and ill-health, the JD-R model also pays attention to stimulating job characteristics and well-being. This aligns with the growing interest in individuals' optimal functioning and positive experiences at work (Luthans, 2002; Seligman \& Csikszentmihalyi, 2000). Second, most previous models consider a rather limited set of job characteristics and the JD-R model considers a broad variety of job characteristics in relation to employees' well-being.

The JD-R model proposes that all working conditions can be categorized as a demand or resource irrespective of the occupational field. Job demands include any of the physical, social, or psychological requirements of the job that call for sustained mental or 
physical effort. Resources include the physical, social or psychological aspects of the job that meet one of the following criteria: a) serve a functional role in meeting work goals, b) reduce the physiological and/or psychological costs of demands, and/or c) promote personal growth and development (Demerouti et al., 2001). Resources may be drawn from various sources including the overall organization (e.g., pay, job security), interpersonal relationships (e.g., supervisory and peer social support), organization of the work (e.g., clarity of work roles, decision making authority), or at the task level (e.g., task significance; Bakker \& Demerouti, 2007).

When viewed from a JD-R perspective, supervisor support can be considered a critical resource for many employees facing workplace demands. A supportive supervisor can be a resource that helps individuals avoid burnout by being understanding and flexible with employees when problems arise. Additionally, a supportive supervisor may be more attentive to the needs of his/her employees and may actually help employees to reduce or manage constraints as they occur. Supervisors may do this by offering emotional support or by providing more tangible resources such as better equipment or training. Indeed, a number of researchers have established the use of supervisor support as a resource (Li et al., 2013; Nahrgang et al., 2011; Rhoades \& Eisenberger, 2002). Li et al. (2013) and Nahrgang et al. (2011) frame supervisor support as a resource while demonstrating a negative relationship between resources and emotional exhaustion. Rhoades and Eisenberger (2002) provide a more comprehensive review of the literature on perceived organizational support (POS) and perceived supervisor support (PSS) and discuss their roles as resources. Furthermore, several studies have provided support for 
the importance of supervisor support when dealing with safety. Nahrgang et al. (2011) found that a supportive environment was the most consistent predictor of safety outcomes such as unsafe behavior, and accidents and injuries (negative relationship), and Li et al. (2013) found that supervisor and coworker support could affect safety compliance (positive relationship). Additionally, Torp and Grogaard (2009) conducted a multilevel study showing that at the worker level, health, and safety compliance correlated with social support and management support. At the group level, management support correlated significantly with high worker compliance with health and safety routines. These studies provide evidence that having a supportive supervisor can be beneficial for an employee's safety performance.

The theories presented here help to support specific pathways in the model. Yet it is just as likely that these theories could support multiple pathways and likely work in tandem to support the relationships in this study. For example, SET suggests that when an individual acts in a way that benefits another, an implicit obligation is created for future reciprocity (Blau, 1964). In the long run, this implicit obligation can lead to behaviors that benefit the initiating party. When supervisors display supportive behavior that aids an employee and indicates concern for his/her well-being, this can then lead to a sense of obligation by the employee to manifest behaviors that benefit their supervisor and the organization. In other words, if supervisors invest in their employees, employees are likely to feel obligated to reciprocate by doing what is expected of them and performing well. This should also extend to safety performance. Hofmann and Morgeson (1999) provide evidence of these safety related implications by showing that perceived 
organizational support and leader-member exchange were related to safety communication, safety commitment and reduced accidents. Furthermore, just as JD-R can explain the potential moderating influences of supervisor support, it can also explain the impact of workload.

I have proposed that supervisor support will act as a resource for those that report a low calling orientation, yet it is also possible that supervisor support can help those high in calling that may be experiencing high workloads. The JD-R model states that a healthimpairment process takes place wherein job demands lead to the exhaustion of mental and physical resources (Bakker \& Demerouti, 2007). In these situations, employees use performance-protection strategies to maintain performance (Hockey, 1997). They look for less effortful ways to deal with goals they accord lower priority, such as those related to safety (Hansez \& Chmiel, 2010). Employees subject to high work pressure are less inclined to use safety equipment. Mullen (2004) found that performance pressure was an important factor that influences safety behavior at work, because pressured individuals tend to value performance over safety. Other previous research supports the negative relationship between job demands and safety behavior as well (Hansez \& Chmiel, 2010; Nahrgang et al., 2011). Thus, it is argued that job demands in the form of work overload will impact safety behavior among employees. On the other hand, job resources such as supervisor support offer energy that fosters the willingness to dedicate one's effort and abilities to work tasks (Bakker \& Demerouti, 2007). This means that in the context of safety, job resources give employees the power to focus their efforts toward working safely and maintaining safety in the workplace. Employees with high job resources are 
motivated to ensure they do not exceed their workload limits.

In this chapter, I detailed the theories that will support the hypotheses in this study. In the next chapter, I present a more targeted overview of these theories and detail the hypotheses under investigation. 
Chapter 6

Hypotheses

In the last chapter, I called upon Social Exchange Theory (SET) to explicate how when one is invested in their role they will also internalize the goals of the organization. In this chapter I build upon that framework to argue the relationships of this study.

Contemporary social exchange theory (see Cropanzano \& Mitchell, 2005) conceptualizes social exchange as a type of interpersonal relationship based on normative rules that are established within unique exchange relationships (Colquitt et al., 2013; Emerson, 1976; Gouldner, 1960). The norm of reciprocity has been commonly studied in relation to social exchange in organizational behavior research (Cropanzano \& Mitchell, 2005). Reciprocity is generally recognized as a universal norm (Gouldner, 1960), and involves "repaying the actions of others with corresponding actions of our own" (Cropanzano, Byrne, Bobocel, \& Rupp, 2001: 184). For example, when employees feel their goals are fulfilled, social exchange mechanisms are activated (such as mutual feelings of trust, support, and commitment). This leads the employee to feel obligated to reciprocate in a positive manner, such as through the support of organizational goals. Further, given that safety is one of the most important goals within the USFS then I am expecting with my first hypotheses that calling is positively related to safety motivation and safety compliance.

Hypothesis 1: Calling is positively related to a) safety motivation and b) safety compliance. 
SET and Psychological Contract Theory, which is housed within SET, can also explain how workload may impact the relationship between calling and safety. SET explains that the relationships that we build with each other occur through a series of interdependent exchanges meant to generate obligations (Cropanzano \& Mitchell, 2005; Emerson, 1976). Psychological Contract theory builds on this set of exchanges to maintain that employees form beliefs that there are mutual obligations between themselves and their employers. These beliefs constitute their psychological contracts (Rousseau, 1995). Employers are obligated to provide certain resources including socioemotional resources, and employees are obligated to contribute to the organization through their efforts and loyalty. Thus, if an employee has been meeting his or her obligations to the employer and the employer reneges, an inequity in the exchange relationship occurs which may result in neglect of responsibilities or obligations, voicing of concern about the inequity, and reduction of commitment and loyalty to the organization (Wayne, Shore, Bommer, \& Tetrick, 2002). It is therefore argued if workload is perceived to be overwhelming and a barrier to accomplishing one's goals then it could be perceived as a breach to the psychological contract. Therefore, I propose, utilizing PCT, that the positive relationship between calling and safety is attenuated under conditions of high workload. Why this breach of contract may be more salient for those that are high in calling was discussed above in the Theory Chapter. My second hypothesis investigates the moderating influences of workload in the positive relationship between calling and the safety outcomes. 
Hypothesis 2: Workload will moderate the relationship between a) safety motivation and b) safety compliance such that under conditions of high workload the positive relationship between calling and safety is lessened.

This study also utilizes the tenants of the Job Demands and Resources (JD-R) Model (Demerouti et al., 2001) to describe how and why supervisor support may moderate the relationship between calling and the safety outcomes. The JD-R model assumes a dynamic set of interrelationships between demands and resources and their subsequent impact on both positive (e.g., employee engagement) and negative (e.g., job burnout) indicators of employee well-being (Bakker, Hakanen, Demerouti, \& Xanthopoulou 2007). In the context of this study, supervisor support is categorized as a resource that serves a functional role in meeting work goals. As such, in the USFS where safety is a top organizational goal, the argument is that supervisor support may facilitate the alignment of individual and organizational goals in those with low calling orientation. That is, my third hypothesis maintains that supervisor support will have moderating influences in the positive relationship between calling and the safety outcomes. And, in particular, supervisor support is especially key for those who report a low calling orientation.

Hypothesis 3: Supervisor support will moderate the relationship between a) safety motivation and b) safety compliance such that under conditions of high supervisor support the positive relationship between calling and safety is strengthened.

Finally, when examining supervisor support as a resource and keeping within the criteria of the JD-R, this study will also investigate the role that supervisor support has in 
buffering the moderating influence of workload on the relationship between calling and safety (Hammer et al., 2016). Thus, this study then asks, could supervisor support act as a buffer for those who are also experiencing heavy workloads and is this more beneficial for those low or high in calling? To explore this question this study will investigate a potential three-way interaction as research question and not as a hypothesis.

Research Question 1: Can supervisor support impact the moderating effects of high workload and calling on safety motivation and safety participation?

These two theories work in concert to support the underlying rationale of this dissertation. That is, although the tenants of Social Exchange Theory can help predict how calling relates to safety as well as the moderating influences on workload, it can also work to explain the moderating influences of supervisor support by characterizing the supervisor as a key part of the exchange relationship. Alternatively, the JD-R can also help to explain the impact of workload by characterizing workload as a demand. Thus, although, I proposed a set of hypotheses each justified by the two theories reviewed here, I am suggesting that these theories could also support multiple pathways. 


\section{Chapter 7}

\section{Method}

The work for this dissertation was hosted by the Unites States Forest Service (USFS) and was part of a larger study titled, "Supervisor Training and Team Education Program (STTEP)”. STTEP was conducted by the Oregon Healthy Workforce Center (OHWC), a NIOSH Center of Excellence. The purpose of STTEP was to investigate current work practices and culture within the USFS to ascertain potential points of intervention meant to improve employee health and safety.

The Forest Service functions within the U.S. Department of Agriculture (USDA), with permanent and temporary seasonal employees that exceeds 40,000 employees during the peak summer work season. Established in 1905 to sustainably manage national forests and promote conservation across the land, currently the Forest Service manages a system of 154 national forests and 20 national grasslands. The Forest Service conducts research to address issues of environmental and social concern and operates a network of research units, laboratories, and experimental forests and rangelands.

Phase I and Phase II were conducted in Oregon within Region 6 of the USFS. Region 6, in Oregon and Washington, manages 17 National Forests, a National Scenic Area, a National Grassland, and two National Volcanic Monuments (USFS, 2016). The two phases of the study were split and conducted at different time points and in different forests.

Phase I took place in one forest located in Northern Oregon and consisted of several meetings with Forest Management and Union Representatives, informational 
interviews with key supervisors, interviews with employees, job shadow sessions, and a survey distribution. Meetings with Forest Management and Union representatives were a primary source of initial information on the organizational structure and culture of the USFS. These were open-ended meetings in which members of the USFS were asked to reflect on potential areas in which improvements could be made regarding employee health and safety. Two informational interviews occurred with three key supervisors. These interviews were semi-structured and focused on stressors that certain work groups may face. For example, one informational interview was with a supervisor in Natural Resources who highlighted safety and health concerns of the work associated with this department. As mentioned in the introduction, the research questions proposed in this dissertation are a direct result of these meetings and interviews. The USFS supervisors noted that many of their employees were highly passionate about their jobs yet due a large workforce reduction the supervisors felt their employees were placed under undue stress. Further, this reduction of staff decreased the number of supervisors and often the employee and supervisor were in differing locations and had few daily interactions. This dissertation work is an attempt to understand how this high "passion" impacts safety under differing conditions of workload and supervisor support.

There were a total of 212 employees across 5 districts during the recruitment period (i.e., March - November 2015) in the Phase I forest. All employees were invited to participate in the pilot study. Participants for the interviews and job shadows were recruited informally through word of mouth. Participants for the survey were recruited using a variety of strategies including: 1) email to all employees from an internal Safety 
and Occupational Health Specialist 2) flyers advertising the study in prominent areas within each district, and 3) five in-person recruitment sessions lasting 4 hours each at each district.

Nine employees volunteered to be interviewed about their work practices, potential challenges, and their health and/or safety concerns. All interviews took place inperson and on-site and averaged 60 minutes. Job shadows of three employees occurred both in the office and in the field and averaged 8.25 hours per employee.

Surveys were distributed to all employees via Survey Gizmo, an online survey platform. A link to the survey was provided in all email communications and on all flyers. Electronic (via iPads) and paper surveys were also distributed at the five, 4-hour on-site visits. Questions for the survey were selected based on the qualitative work (i.e., the interviews and job shadows), previous research conducted within Region 3 of the USFS (Demsky \& Fritz, 2015), and meetings with USFS leadership. A total of 65 employees participate in the survey for a response rate of $31 \%$. This response rate is the exact response rate found in the Region 3 report (Demsky \& Fritz, 2015) thus is on par with previous work within the USFS.

Phase II was conducted with two Southern Oregon forests from June 2016December 2016. The primary purpose of Phase II was to support this dissertation work but also to further investigate work environment, supervisor structure, and worker wellbeing with the aim of developing an intervention. The research design mirrored Phase I in which several meetings with Forest Management, interviews with employees, job shadow sessions, and a survey distribution were conducted. 
There was a total of 400 employees across 12 districts during the recruitment period in the two Phase II forests. As with Phase I, all employees were invited to participate. Participants for the interviews and job shadows were recruited informally. Participants for the survey were recruited using the same strategies as in Phase I including: 1) email to all employees from the internal Safety and Occupational Health Specialists at each forest 2) flyers advertising the study in prominent areas within each forest, and 3) four in-person recruitment sessions at three of the 12 districts.

Eight employees volunteered to be interviewed about their work practices, potential challenges, and their health and/or safety concerns. All but one interview took place in-person and on-site and averaged 60 minutes. One interview took place over the phone and lasted 45 minutes. Job shadows of four employees occurred both in the office and in the field and averaged 8.25 hours per employee. Surveys for Phase II were distributed to all employees via Qualtrics. A link to the survey was provided in all email communications and on all flyers. Fifteen paper and pen surveys were collected during the three site visits. A total of 122 employees participated in the survey for a response rate of $32 \%$. This response rate is on par with response rate in Phase I.

On the basis of an a priori analysis of power with the anticipated number of predictors (from 2-6 depending on analysis) and an anticipation of a small effect size determined by using the Cohen $\mathrm{f}$ - squared estimations in which a sample of at least 478485 participants would be needed to yield sufficient power for the hierarchical regression analyses (Soper, 2016). Several recruitment strategies were utilized to increase sample size including in-person recruitment periods and multiple site visits, but in the end, I was 
only able to sample from three forests limiting the possible sample size. Furthermore, although only a small effect size was expected due to the importance of safety and possible extreme negative consequences of unsafe practices the study had theoretical and practical value.

To increase the power of the study and due to the similarity of the samples the data across all three forests was combined to create a final sample (See Table 1 for a breakdown of participants). After removing participants who reported no data on either the independent variables and/or one of the dependent variables the full survey sample is 183. A post hoc analysis of power confirmed the need for a larger sample. Using a number of predictors (from 2-6 depending on analysis) and a small effect size as determined by using the Cohen f- squared estimations a sample of 183 participants yielded a $.38-.48$ probability of detecting an effect when there is an effect there to be detected (Faul, Erdfelder, Buchner, \& Lang, 2009).

A total of 24 employees volunteered to either be interviewed or to be shadowed. To protect the anonymity of this small sample no demographics were collected. The survey participants reported an average age of $46.59(S D=11.90)$, were male $(49.7 \%)$, married (59.4\%), had an average tenure at the current forest of 10.68 years and average tenure at the USFS of 18.66 years. Most were White (73.2\%) and the remaining selfidentified as American Indian or Alaska Native (4.9\%), Asian (3.8\%), Multiracial (5.5\%) or reported other $(2.2 \%)$. See Table 2 for an overview of all the participant demographics.

The majority of the survey participants reported that they were employees with non-supervisory status, were permanent full-time employees who worked on average 
42.47 hours per week, and worked in Natural Resources. See Table 3 for an overview of the survey participants' job characteristics.

Cross-sectional design. This study utilized a cross-sectional design. Although cross-sectional designs fail to tell us about cause and effect they can be useful in helping to determine important links and associations that have yet to be investigated. In this case, the relationship between calling and safety has yet to be established, thus this crosssectional design can help inform the literature. By knowing which associations are the strongest, this study can assist future work in developing theory. That is, this study could be thought of as part of the progression of research in which associations are made, lending to development of research questions aimed at studying these associations over time, as well as the goal the development of interventions or trainings meant to improve upon the potential positive association between calling and safety. Furthermore, crosssectional designs allow for the investigation of under-investigated associations without placing an undue burden on the data collection site. In the case of this study, by employing a cross-sectional design, I am able to collect information that serves not only this dissertation study but also the needs of the USFS in such a way that protects the anonymity of the employees as well as their time. As indicated in the pilot work, the USFS employees have already indicated that workload is a key stressor, this study's design balances the needs of the study with the constraints within the organization.

\section{Measures}

A number of established measures were used in this study. A description of all measures is listed below. See Appendix B for a list of all the survey items. 
Calling Scale. The 12-item Calling Scale developed by Dobrow and Tosti-Kharas (2011) was used to measure the degree to which participants feel called to their position. In four separate samples, the scale developers found that internal consistency reliability scores were very good: high school students pursuing music $(\alpha=.88)$, high school students pursuing performing arts or writing $(\alpha=.90)$, undergraduate and graduate business students $(\alpha=.90)$, and professional managers $(\alpha=.94)$. Across their four samples, the inter-item correlations were sufficient and ranged from .41 to .73 (Mean $r=$ .63). An exploratory factor analysis (EFA) was conducted on the various samples, and test developers found that two factors emerged for the high school musicians and high school performing artists; however, a Scree test was conducted and all four samples revealed a single factor structure (Dobrow \& Tosti-Kharas, 2011). On the basis of the theoretical underpinnings of the calling construct, scale developers conducted a confirmatory factor analysis (CFA) to determine the fit of a model whereby all 12 items loaded on one factor. Fit index results suggest that the model fit was adequate (Comparative Fit Index $=.90 ;$ Standardized Root-Squared Mean Residual $=.06)$. To examine the convergent validity of this newly developed calling scale, researchers administered it alongside three other established scales: Calling Orientation Scale (Wrzesniewski et al., 1997), Neoclassical Calling Scale (Bunderson \& Thompson, 2009), and 2-item Calling Scale (Duffy \& Sedlacek, 2007). As anticipated, the 12-items were significantly related to all three scales.

A sample item for the scale is "When I describe myself to others, the first thing I often think about is the work I do with the forest.". Study participants responded to 
statements on a 7-point Likert scale $(1$ = Strongly Disagree, 2 = Moderately Disagree, $3=$ Slightly Disagree, 4 = Neither Agree or Disagree, $5=$ Slightly Agree, 6= Moderately Agree, $7=$ Strongly Agree). The measure had an alpha of .88 in this sample. The mean was $4.65(S D=1.11)$ indicating a higher than average calling orientation.

Quantitative Workload Inventory (QWI). This is a 5-item scale developed by Spector and Jex, (1998) and is commonly used to assess the volume or perceived amount of work required of the employee and includes both workload and work pace. A sample item for the scale is "How often does your job require you to work very fast". Participants responded to statements on a 5-point Likert scale $(1=$ Less than once per month or never, $2=$ Once or twice per month, $3=$ Once or twice per week, $4=$ Once or twice per day, $5=$ Several times per day). The measure had an alpha of .87 . The mean was $3.52(S D=1.01)$ indicating that on average workload was impacting employees weekly.

Supervisor Support. This 3-item scale was developed by Yoon and Lim (1999) and was selected due to its brevity and its use in other OHWC interventions studies. A sample item for the scale is "My supervisor can be relied upon when things get tough on my job". Pilot study participants responded to statements on a 5-point Likert scale $(1=$ Strongly Disagree, 2 = Disagree, $3=$ Neither Agree or Disagree, $4=$ Agree, $5=$ Strongly Agree). The measure had an alpha of .78. The mean was $4.02(S D=1.02)$ indicating that on average employees felt support from their supervisors.

Safety Measures. Safety compliance refers to following established safety-related policies and procedures in line with one's job description, while safety participation, like 
contextual performance, contributes to creating a positive organizational environment for safety and often includes behaviors that are outside of one's official job description. Safety compliance was measured using three items (Neal et al., 2000). An example item is, "I use the correct safety procedures for carrying out my job". Safety motivation was also measured using three items (Neal et al., 2000), an example of which is, "I put in extra effort to improve the safety of the workplace". Participants responded to statements on a 5-point Likert scale $(1=$ Strongly Disagree, $2=$ Disagree, $3=$ Neither Agree or Disagree, $4=$ Agree, $5=$ Strongly Agree). The safety compliance scale had an alpha of .95 while safety motivation had an alpha of .93 . The mean for safety compliance was $4.33(S D=.73)$ while safety motivation had a mean of $4.55(S D=.67)$ indicating that on average employees reported they were motivated and behaved safely.

Control Variables. Control variables were considered for inclusion on the final analyses based on their potential relationships with the investigated variables in keeping with the direction of literature to minimize the use and misuse of control variables (Spector \& Brannick, 2011). The use of one control variable, tenure, was based on theoretical rationale and its relationships with both the independent and dependent variables. Previous research has acknowledged tenure can impact both calling (Cardador et al., 2011) and safety (Beus, Bergman, \& Payne, 2010).

\section{Analysis Strategy}

Prior to hypothesis testing, the data were cleaned and screened for missing data. All predictor variables were mean-centered to aid in interpretation of the results. Reliability of each scale was assessed. Data were analyzed using general linear regression 
using the PROCESS macro created by Hayes (2013) for SPSS. The PROCESS macro allows for testing of both simple and complex moderation hypotheses. 


\section{Chapter 8}

Results

\section{Descriptive Statistics}

Means, standard deviations, correlations, and reliability coefficients are presented in Table 4. Overall, the means for calling and the safety variables were high. Calling had a mean of 4.65 on a 1-7 scale, and both safety motivation and safety compliance were above 4 on a 1-5 scale. Although not significant, calling was positively associated with both safety motivation and safety compliance. Supervisor support and workload also had high means. Supervisor support had a mean of 4.06 whereas workload had a mean of 3.52 , both on a 1-5 scale. Supervisor support was significantly associated with workload and safety motivation in the expected directions. Tenure and safety compliance were found to be related such that as tenure went up so did safety compliance. Tenure was both omitted and included in the below analyses with no change to the overall results. As such, given the theoretical rationale, as noted above, tenure was included as a control variable

\section{Hypothesis Testing}

My hypotheses (1a-b through 3a-b) posited that there would be a main effect of calling predicting safety motivation and safety compliance and that this relationship would be moderated by workload and supervisor support. Hypotheses 1a-b and 2a-b were tested using linear regression. Tenure was added to the model as a control variable but not found to be predictive of safety motivation $(B=-.01, \mathrm{SE}=.01, p=.75)$ or safety compliance $(B=.01, \mathrm{SE}=.01, p=.28)$. Calling, workload, and the interaction between the two variables were added to the model predicting safety motivation and safety 
compliance. Results indicated that there was no main effect relationship of calling on safety motivation $(B=.05, \mathrm{SE}=.05, p=.33)$ nor safety compliance $(B=.07, \mathrm{SE}=.05, p$ $=.21)$. Furthermore, the interaction terms were not significant, indicating that the relationships between calling and safety motivation $(B=.05, \mathrm{SE}=.05, p=.24)$ and calling and safety compliance $(B=.05, \mathrm{SE}=.05, p=.35)$ were not dependent on workload. The model summary and parameter estimates are shown in Table 5 and Table 6.

This same process was repeated to test Hypothesis $3 \mathrm{a}-\mathrm{b}$. Tenure was once again added to the model as a control variable but not found to be predictive of safety motivation $(B=-.01, \mathrm{SE}=.01, p=.77)$ or safety compliance $(B=.01, \mathrm{SE}=.01, p=.25)$. Calling, supervisor support, and the interaction between the two variables were added to the model predicting safety motivation and safety compliance. Results indicated that there was no main effect relationship of calling on safety motivation $(B=.05, \mathrm{SE}=.05, p$ $=.30)$ nor safety compliance $(B=.07, \mathrm{SE}=.05, p=.20)$. Furthermore, the interaction term was not significant indicating that the relationships between calling and safety motivation $(B=-.05, \mathrm{SE}=.05, p=.29)$ and calling and safety compliance $(B=-.03, \mathrm{SE}=$ $.05, p=.53)$ were not dependent on supervisor support. The model summary and parameter estimates are shown in Table 7 and Table 8.

The same process was repeated to test the research question. Tenure was once again added to the model as a control variable but not found to be predictive of safety motivation $(B=. .01, \mathrm{SE}=.01, p=.78)$ or safety compliance $(B=.01, \mathrm{SE}=.01, p=.27)$. Calling, supervisor support, the interaction between the two variables, and the three-way 
interaction were added to the model predicting safety motivation and safety compliance.

Results indicated that there was no main effect relationship of calling on safety

motivation $(B=.05, \mathrm{SE}=.04, p=.31)$ nor safety compliance $(B=.06, \mathrm{SE}=.05, p=.22)$.

Finally, the three-way interaction was not significant $(B=-.04, \mathrm{SE}=.05, p=.43)$ for safety motivation nor safety compliance $(B=-.02, \mathrm{SE}=.05, p=.68)$. The model summary and parameter estimates are shown in Table 9 and Table 10. 


\section{Chapter 9}

\section{Discussion}

This study examined the role of calling on safety motivation and safety compliance. The study also assessed if workload and supervisor support would act as moderators in the relationship between calling and the safety outcomes within a sample of USFS employees. In summary, my study sought to understand the relationship between calling and safety.

The correlation matrix revealed no relationships between calling and the other variables under investigation. However, a significant positive correlation was found between tenure and safety compliance. This suggests, at a correlational level, that those with longer tenure are more likely to behave safely. A couple of studies directly measure this relationship with conflicting results. Beus, Bergman, and Payne (2010) examined the relationship between the organizational tenure of employees at a given worksite and safety climate strength. Safety climate has demonstrated positive associations with safety compliance and participation (Clarke, 2006; Nahrgang et al., 2011) and negative associations with workplace accidents and injuries (Hofmann \& Stetzer, 1996; Probst, 2004). Beus et al. (2010) found tenure was significantly positively related to climate strength indicating that tenure plays a role in safety behaviors. Yet, in a study of Chinese construction workers Siu, Phillips, and Leung (2003) found that tenure was a significant predictor of occupational injuries. That is more tenure was related to more reported injuries. These authors argue that those with longer working experience may be more likely to comply with rules and were more open to reporting minor injuries at work. This 
reasoning may also explain why tenure was more related to compliance than motivation in my study. It may be that those with high tenure are more likely to follow the rules even under situations of low motivation. In turn, this may also help to explain the results of the Beus et al. (2010) study; it may be that those with long tenure are more likely to be embedded into the organizational climate (in this case safety climate) and behave accordingly even in the face of low motivation.

Other correlational relationships were found in the present study. In particular, supervisor support was found to be negatively related to workload and positively related to safety motivation. This mirrors the research question under investigation in my study in which it was argued that under conditions of high workload those with high calling would be less likely to behave safely but that this relationship could be moderated by supervisor support. Although the research question in my study found null results, it does appear that supervisor support, workload, and safety motivation may have some relationship. In fact, in their meta-analysis and as discussed above, Nahrgang et al. (2011) utilized the JD-R to examine the impact of burnout and engagement on safety outcomes. The authors indicated that job demands, such as workload, would relate to burnout and in turn negatively impact safety outcomes. The authors also found the converse to be true in that job resources, such as supervisor support, related to engagement, which in turn positively impacted safety outcomes. In my study, it was theorized using the tenets of the JD-R and the empirical evidence provided by Nahrgang et al. that calling would act as a resource which in turn would impact the underlying mechanisms related to safety. 
Given the cross-sectional design it was beyond the present study to examine the mechanisms in play, but as shown in post hoc analyses (see Appendix C), the correlation matrix does provide some evidence that this reasoning was justified. Emotional exhaustion, a component of burnout, was found to be related in the expected directions to all potential demand variables (i.e., workload, role ambiguity, work-family conflict) and resource variables (i.e., perceived organizational support, decision-making authority, supervisor support). Furthermore, calling was negatively related to emotional exhaustion providing some support for the framing of calling as a resource. Finally, emotional exhaustion was found to be related in the expected direction with all the safety variables collected in the broader study.

The overall purpose of my study was to investigate how and in what ways, calling would relate to safety. Unfortunately, my study cannot yet answer the question in a definitive way. Hypothesis 1 posited that calling would be positively related to safety motivation and safety compliance. Hypothesis 2 suggested that workload would moderate the relationship between calling and safety motivation and safety compliance in that under conditions of high workloads the positive relationship between calling and the safety outcomes would be attenuated. Hypothesis 3 suggested that supervisor support would moderate the relationship between calling and safety motivation and safety compliance in that under conditions of high supervisor support the positive relationship between calling and the safety outcomes would be strengthened. All three hypotheses were found not to be supported. Below I discuss a myriad of reasons why this may be. 
The present study aimed to examine an individual difference (i.e., calling) variable as it relates to safety motivation and compliance. Although initial efforts at identifying an "accident prone" personality were inconsistent and inconclusive (e.g., Visser, Pijl, Stolk, Neeleman, \& Rosmalen, 2007), recent research has found consistent relationships between personality and safety-related behavior. Notably, Beus, Dhanani, and McCord (2015) found that agreeableness and conscientiousness were negatively associated with unsafe behavior (see also Clarke \& Robertson, 2005), and that sensationseeking is positively and more strongly related to unsafe behavior than its parent trait (i.e., extraversion). Although recent research has demonstrated consistent relationships, this stream of research also indicates that safety climate perceptions are often the more important predictor of safety-related behavior than personality. It is possible that calling is too distal a predictor to have an impact on safety. In fact, findings in the calling literature suggest that the relation of calling to criterion variables, such as job satisfaction and work engagement, is typically mediated by work meaning and other variables (e.g., career commitment). For example, studies have found that the relation of calling to job satisfaction in employed adults was mediated by career commitment (Duffy et al., 2011a) or by both career commitment and work meaning (Duffy et al., 2012). A few studies have examined calling-criterion relations longitudinally and have found that the predominant paths tend to be from other variables such as life meaning (Duffy et al., 2011b) or career commitment, work meaning, and job satisfaction (Duffy et al., 2014) to calling. Duffy et al. (2014) also found reciprocal paths from calling and the criterion variables of work and life meaning. 
Although cross-sectional data can provide an initial look into potential unexplored associations as it did here, it comes with some limitations. One such limitation is the inability to test mediators. There are ways to statistically test mediators with crosssectional data but this is not traditionally recommended (Aguinis, Edwards, \& Bradley, 2016). In this study, I argued that one will espouse the organizational goals of safety due to a variety of mechanisms. First is the assumption that calling will lead one to be heavily invested in their work role. This assumption is common in the calling literature, and, in fact, role investment is a key underlying definition of calling. An examination of the calling measure attests to this assumption. Second, I have argued that one with a higher calling is working to fulfill a certain goal. Further, one that is trying to fulfill their goals sees their organization as key to that goal fulfillment. As an example, a fish biologist may want to study a certain species of fish and will see the USFS as one vehicle for not only studying that species but also as an entity that espouses the same values of fish preservation. Within these assumptions are unmeasured and unexplored mechanisms. That is, the link from calling to safety may be too big of a leap that misses key steppingstones due to its cross-sectional design.

The results of my study may have been unsupported due to the possible moderating factor of workload. The JD-R model, as outlined above, is a comprehensive job characteristics model. It categorizes the health-impairing aspects in the work context (e.g., workload, emotional demands) as job demands and the stimulating job characteristics (e.g., task autonomy, positive feedback) as job resources. Some JD-R studies have, however, shown that particular job demands (i.e., workload, cognitive 
demands) are positively associated with positive outcomes such as engagement (Bakker, Demerouti, \& Schaufeli, 2005), indicating that workload may be more complex than proposed in this study. Some researchers have argued that workload is a challenge stressor (i.e., a job demand that people appraise positively; LePine, Podsakoff, \& LePine, 2005), but more often researchers have investigated workload within the framework of occupational stressors and posited negative appraisals (e.g., Kawada \& Otsuka, 2011; Posig \& Kickul, 2003; Spector \& Jex, 1998) as with my study’s proposition. In this USFS sample, participants reported high workloads but USFS leadership indicated that often this workload was self-imposed. That is, USFS leaders knew that the reduction in workforce would increase workloads and in response, leaders and supervisors would ask employees to reduce their efforts and performance levels, yet, these same leaders acknowledged that employees were unwilling to "let things go" and were often working long hours, at times they suspected with no pay. It may be that self-imposed workload has differing impacts than organizationally imposed workloads. It is also possible that the relation between workload and its outcomes may be an inverted U-shape (Bakker et al., 2005; Mauno et al., 2007). Such quadratic relations have, however, received only limited empirical support (Rydstedt, Ferrie, \& Head, 2006). Therefore, Taris (2006) argued that the idea of a quadratic relationship represents an "urban myth" which, in his view, does not deserve further testing yet these arguments may be useful when examining highly engaged workforces. A deeper investigation of workload in these highly engaged and "called" samples would be a useful endeavor moving forward. 
Finally, measurement issues may have contributed to the null results. Statistical conclusion validity relates to the truth or approximate truth of the null hypothesis and states that it is possible to reach an incorrect conclusion about the relationship in the observations with two kinds of errors, (1) to conclude that there is no relationship when in fact there is, (2) to conclude that there is a relationship when in fact there is not. According to Cook and Campbell (1979), restriction of range is one of many threats to statistical conclusion validity. In the present study, the independent and dependent variables had very high means. Calling was measured on a 1-7 scale and had a mean value of 4.66. Safety motivation and safety compliance both measured on a 1-5 scale had means above 4 . Respondents tended to use only the higher end of the scale for both variables creating a restriction of range. This range restriction makes sense because the USFS values safety and second, the sample was primarily composed of those with long tenure who may have been more likely to espouse safety and have found a fit between their calling and their organization. Finally, my study may have been underpowered. An a priori power analysis indicated that a sample size of at least 475 was needed to find a small effect. Although a number of recruitment and relationship building strategies occurred between the two data collection periods, in the end data were collected from 183 participants. A post hoc power analyses has indicated with this sample size I had a .38.48 probability of detecting a small effect if one was present. In summary, it is possible that unexplored mechanisms and moderators, an overemphasis on individual differences, and measurement issues may have contributed to the null results. 


\section{Study Implications}

The present study was the first study to investigate the link between calling and safety. Thus, a number of theories were used to support the assumptions behind the proposed associations. Much of the early research on calling was inductive in nature, with scholars explaining patterns of relationships without a clearly articulated overarching conceptual framework (Dik \& Duffy, 2012). This is an understandable and useful starting point, but as scholarship on calling has begun to mature, the need for theory to guide the path forward has become obvious. My study attempts to fill this theoretical gap. Of particular interest and as discussed next, I argue that psychological contract breach is the vehicle to understanding the calling literature.

Psychological contract theory has distinguished two distinctive forms of psychological contracts in employment relations, namely transactional and relational psychological contracts (Restubog, Hornsey, Bordia, \& Esposo, 2008; Zagenczyk, Restubog, Kiewitz, Kiazad, \& Tang, 2014). A transactional contract is typically narrowfocused and has a purely economic, monetary emphasis. As such, employees with a transaction-oriented psychological contract are more likely to quit their jobs as they tend to use their current position as a stepping stone to gain better ones (Raja, Johns, \& Ntalianis, 2004; Rousseau, 1990). Relational psychological contracts are based on a longterm employment relationship grounded in relational and socioemotional exchanges (Hui et al., 2004; Millward \& Hopkins, 1998). Employees with relational psychological contracts highly value their relationship with the organization, and are interested in securing long-term employment (Chang et al., 2013). By implication, they often act as 
organizational citizens by performing above and beyond their assigned duties and responsibilities to promote organizational success (Rousseau, 1995). Supporting this assertion, Millward and Hopkins (1998) found that employees with relational psychological contracts undertake a high number of extra hours worked per week without pay.

It was argued throughout this dissertation that those with high calling will identify more with the goals of the organization through a series of social exchanges and relational psychological contracts. As such, the positive outcomes associated with calling may in fact be due to the "contracts" they have formed with their organization. Yet, while calling has been studied in working populations to understand organizational outcomes, there is little work done to understand the relationship between the organization and the employee. That is, we have yet to explore the interface between the "called" employee and the organization in which they work. Therefore, little is known about what occurs when there is a breach of contract for those with high calling. One study participant noted, "We are always balancing overloaded priorities. Workload is a huge challenge, as well as unwillingness to give up important things." My study asserts that a high workload could signal a breach of contract especially for those in a helping field. As the quote alludes to when one is highly passionate about who or what they are "helping" a high workload may be seen as a barrier to accomplishing this goal. Furthermore, it has been suggested that individual differences shape psychological contracts by influencing employees' choice of tasks and how they construe and enact contract terms (Raja et al., 2004). A small number of studies have examined the effects of individual differences on 
psychological contracts but they find a wide range of influencing factors including occupational and exchange ideologies (Bunderson, 2001; Coyle-Shapiro \& Neuman, 2004), personal and social identities (Hallier \& Forbes, 2004), and work values (De Vos, Buyens \& Schalk, 2005). These studies tangentially suggest that calling, framed as an individual difference, may relate to the perception of a breach of psychological contract. Given the wealth of research examining the negative consequences of a perceived breach of contract including abusive supervision (Wei \& Si, 2013), job attitudes, actual turnover, organizational citizenship behavior, and in-role performance (Zhao, Wayne, Glibkowski, \& Bravo, 2007) my study could provide an important first step towards a fruitful area of future research. Finally, as noted by Tetrick and Peiró (2016), it is surprising given the wealth of research on other performance indicators that the safety literature has not also examined the role of psychological breach and safety performance. The present study attempts to bridge this theoretical gap.

Further, the generally consistent links found between calling and positive outcomes makes calling a potential target for individual and organizational interventions designed to increase people's ability to discern and live out a calling. To date, one empirical study (Dik \& Steger, 2008) and three practice-focused journal articles (Adams, 2012; Dik, Duffy, \& Eldridge, 2009; Dik, Duffy, \& Steger, 2012) have addressed this issue directly. Generally, these authors suggest that the best way to discern one's calling is related to an openness to new directions, actively exploring one's interests, values, and skills and how these match with potential jobs, and connecting one's work with a tangible, pro-socially-oriented purpose. Yet, more research is needed to ascertain if 
calling can be "trained." In terms of living out a calling, it is suggested that individuals actively craft their current job to make it more meaningful or more pro-social (Berg et al., 2010) and, if that is too difficult or impossible, explore ways to live out their callings outside of work. In the current sample, one side effect of the reduction in workforce is that participants were taking on multiple roles, often crafting their jobs. Although this at times appeared to lead to role ambiguity, it may have also led to a higher ability to live out a calling.

The current study also aimed to understand calling in a "helping field." Gifford Pinchot, the first Chief of the Forest Service, summed up the purpose of the Forest Service as "to provide the greatest amount of good for the greatest amount of people in the long run." (USFS, 2015). This purpose is characterized further by the USFS slogan: Caring for the Land and Serving People. This mission and its accompanying slogan were espoused and reiterated by all whom I interviewed and it gave my study its perspective on the impact of calling. While not traditionally thought of as a helping field, Forest Service work encompasses a range of occupations all focused on the preservation of the land and inhabitant species populations through education and research along with a commitment to the public. As noted previously, it may be especially important to study calling within these occupations as it pertains to a breach of psychological contract.

Furthermore, it may be that there are more employees with a high calling orientation in helping fields given the underpinning of work meaningfulness and prosocial motivation in the definition of calling. On one hand, this should lead to an engaged, proactive, and committed workforce. On the other hand, it could lead to greater 
burnout and turnover should these employees experience barriers to fulfilling their calling. As an example, Hartnett and Kline (2005) recommend that teacher educators provide student teachers a realistic job preview to reduce the "fall from the call" that they feel explains the high rates of teacher turnover. My study, with its high mean on the calling measure, suggests exploring calling in other "helping" fields may add to what we know about the interaction between the called employee and the organization in which they work.

Finally, as noted in the introduction, due to overwhelmingly negative consequences associated with accidents and injuries, illuminating a potential predictor of safety is critical. Should this line of calling research continue it is quite possible that safety scholars might investigate the role of calling and similar constructs as potential levers for intervention work. This dissertation has informed the recruitment strategies and intervention design of the larger and currently in-progress Phase III study, in which the USFS is testing an intervention aimed at reducing role ambiguity and increasing supervisor support for work-life balance and safety behaviors. Thus, while the relationships under investigation in my study were found to be unsupported, other measures collected as part of the larger data collection effort were instrumental in laying the groundwork for the Phase III intervention work.

\section{Potential Limitations and Future Work}

My study, as with many other studies, has a number of limitations. These limitations become even more salient when hypotheses are unsupported. Above, I highlight a number of possible reasons why the study did not go as planned. In particular, 
I speak to untested mediators and moderators and measurement issues. I expand on these points here and describe how research could move forward.

Given the results of the study, it is important to question the validity of the constructs under investigation. Of all the proposed constructs, calling is the least examined. Further, as noted in Chapter 2 there are still arguments in the field regarding how to define calling. For example, calling has been found to be related to work meaning and career commitment. Steger, Dik, and Duffy (2012) in the development of a measure of work meaning found this new measure correlated strongly with measures of calling as well as with career commitment and job satisfaction. It was also found to predict job and life satisfaction beyond the effects of calling and it was argued whether or not calling offered a unique predictive value. In this study, I used the Dobrow and Tosti-Kharas scale to measure calling and it could be argued that this scale may have measured aspects of the workplace beyond the scope of calling. In the development of the scale, the authors found a strong correlation between calling with work engagement for the student and employee samples, $r=.80$ and $r=.82$, respectively. It was expected that work engagement would be significantly related to calling work orientation because the construct of calling includes dimensions such as meaningfulness, person-environmental fit, prosocial motivation, and transcendent purpose (Hagmaier \& Abele, 2012). The deep sense of purpose, dedication, and investment in work tends to parallel the characteristics of work engagement (i.e., vigor, dedication, and absorption; Dobrow \& Tosti-Kharas, 2011). A series of factor analyses were conducted in the validation of the Dobrow and Tosti-Kharas scale to establish convergent validity, and findings suggest that calling work 
orientation was related to but distinct from work engagement. However, when two constructs are too highly correlated they may not be sufficiently distinct (Campbell \& Fiske, 1959). According to Berry, Ones, and Sackett (2007), "it is difficult to point to one value as this threshold, but we posit that when the correlation between two constructs approaches values commonly agreed on as acceptable for reliability coefficients (e.g., $r=$ .70 and higher), the distinctiveness of the two constructs becomes questionable" (p. 411). In my study, I utilized a number of theoretical and empirically-based arguments to generate my hypotheses. I posited calling as an individual orientation toward viewing their work as truly meaningful. Therefore, I would argue that work meaning is a mediating factor. I also argued that calling is broader than person-job fit or work engagement. That is, calling is something one possess prior to entering the organization, it is a motivational construct that propels one in a certain career path. It is once in that profession that one would experience greater person-job fit or engagement. Unfortunately, these other constructs were not measured in my study so my assumptions cannot be tested. Future work should focus on construct clarity and the investigation of the incremental validity of calling.

Relatedly, although cross-sectional data has its benefits in investigating relationship that are untested to inform future work in this area, the use of cross-sectional data is limiting. Cross-sectional data does not allow for testing causality and limits our ability to test potentially mediating factors. The use of longitudinal data is needed in future work on calling. In fact, longitudinal data in the calling literature is scant. To my knowledge there are only six studies that examined calling longitudinally (Dobrow \& 
Tosti-Kharas, 2011, 2012; Duffy et al., 2011b, 2014, Hirschi \& Hermann, 2012, 2013). More longitudinal data is needed to develop a strong theoretical basis for how calling develops and changes over time. For example, Duffy et al., $(2012,2013)$ found that the relationship between calling and job satisfaction was mediated by career commitment and work meaning in cross sectional designs. Yet longitudinally Duffy et al., (2011b) found that life meaning, career commitment, work meaning, and job satisfaction predicted calling. Furthermore, Duffy et al. (2014) found reciprocal paths from calling to the criterion variables of work and life meaning. More research is needed to further investigate the role of mediators over time. With longitudinal research designs, we could potentially determine the evolution of calling over one's life and how this could serve as a protective factor, for example, there appears to be a correlational relationship between calling and emotional exhaustion (see Appendix C) suggesting an avenue for future research.

The sample for my study comes from one organization, limiting generalizability. However, this limitation is partially tempered due to the fact that the USFS is a large organization crossing multiple regions with a diversity of occupations. Yet, there could be certain cultural and organizational norms that may not translate into other industries. Relatedly, the two moderating factors were selected based on the pilot work conducted in the USFS. Other moderating factors may be more important in different organizations. My study points to a few that may be telling. As noted, there was a correlation between tenure and safety. It may make sense to examine how tenure relates to the calling and safety relationship. Furthermore, due to the lack of research on the interplay between the 
"called" employee and the organization, much work is needed to examine the contextual factors within the organization. For example, what occurs in organizations with very autonomous cultures? Would a person's calling be more likely to be experienced in certain organizational cultures? In this same vein, more research is needed to examine calling across organizational levels. In my study, calling had a very high mean. Could there be group effects at play? And if so, how can we better understand the role of the organization in promoting calling?

Finally, due to the rarity of measuring near misses, accidents, and injuries, safety motivation and compliance is commonly included in safety-related models as an antecedent of these safety outcomes. However, by only measuring the self-reported safety behaviors, the present study is at risk of social acceptability bias. As noted throughout, the USFS values safety as a key organizational outcome. Could this have biased the results thus limiting this study's potential to find a relationship between calling and safety? It remains for future work to employ objective safety measures in high safety cultures.

The investigation of calling is still in its early stages; therefore, it may be beneficial to highlight findings outside the proposed hypotheses. In the next section, I highlight a few correlational relationships that suggest a need for future research.

Post hoc analyses. In the spirit of moving the calling literature forward (Hollenbeck \& Wright, 2017), it may be worthwhile to look at the other collected variables to see how they are related. These relationships are highlighted below. A list of 
the collected variables along with information about each measure is presented in Appendix C.

The relationship between calling and job satisfaction is robust. Two early studies by Davidson and Caddell (1994) and Wrzesniewski et al. (1997) surveyed working adults to find that those endorsing a calling were more satisfied at work and in their daily lives. A more recent study by Peterson et al. (2009) found calling to moderately correlate with work zest and life satisfaction and strongly correlate with work satisfaction. A study by Bunderson and Thompson (2009) with zookeepers found that the extent to which participants endorsed a calling moderately correlated with occupational identification, occupational importance, work meaningfulness, and perceived organizational duty. Collectively, results from these studies suggest that adults who view their career as a calling appear to have higher levels of well-being, work satisfaction, enjoyment of their work, and occupational commitment. This study also finds that at a correlational level, calling is related to job satisfaction in a sample of USFS employees (see Appendix C).

Where these post hoc analyses break new ground is with the correlations found between calling and decision-making autonomy, POS, and group-level safety climate. Decision-making autonomy, a part of motivational work design approaches (Campion, 1988; Hackman \& Oldham, 1976), is viewed as the amount of freedom and independence an individual has in terms of carrying out his or her work assignment. This was expanded to suggest that autonomy reflects the extent to which a job allows freedom, independence, and discretion to schedule work, make decisions, and choose the methods used to perform tasks (Morgeson \& Humphrey, 2006). While the present study does not 
reveal the exact nature of this relationship, the correlation suggests that those who have more autonomy in the workplace may be better able to enact their calling. That is, it may be that autonomy on some level allows one to craft their job so they in turn are able to focus on their calling. I asked earlier, if calling can be trained, but we also need ask what occurs in organizations in which employees are empowered to make their jobs more meaningful? Can we create organizational environments in which employees are encouraged to seek their calling? Future work should build on these questions to examine if organizational culture and job characteristics are the antecedents to experiencing ones calling. This line of questioning, is important because although the recent calling definition maintains that calling is one that anyone can experience within any domain, calling it is still often thought of as an individual difference. Inquiring beyond the traditional investigated individual antecedents such as employee ability, career-related self-efficacy, and perceptions of career success (Dobrow, 2011; Higgins, Dobrow, \& Chandler, 2008; Ng, Eby, Sorensen, \& Feldman, 2005), could help clarify the dynamics of calling.

In a related fashion, the relationship found between POS and calling aligns with the theory expressed in this study. Social exchange theorists argue that resources and support felt from the organization generate feelings of reciprocity. Throughout I have argued that those with a calling orientation will view the USFS as vehicle for living out their calling which in turn will be linked to their willingness to espouse organizational goals. The fact that POS and calling were correlated supports my argument, and suggests that there are organizational factors which impact the expression of one's calling. As 
mentioned above, much work is needed to understand the interface between the called employee and the organization in which they work. Future work should strive to disentangle the organizational factors that may impact calling and its outcomes. Similarly, group-level safety climate (GSC) is the employee perceptions of their direct supervisors' commitment to and prioritization of safety. Zohar and Luria (2005) found that GSC perceptions partially mediate the relationship between organizational safety climate perceptions and safety behavior. Zohar and Luria's findings suggest that GSC perceptions are more proximal to employees' safety behavior. It may be that climate plays a role in how calling plays out in an organization. As noted above, culture and climate should be examined in order to ascertain how organizations can and do impact the expression of one's calling orientation. This may be especially important for safety outcomes.

Taken together, there remains much work to be done in understanding how calling is manifested in an organization. That is, and as mentioned throughout, there is little research on how organizations hinder or help those with a relevant calling orientation. In some respects, this is to be expected since a person could experience their calling in any multiple organizations. It is the hope these post hoc analyses expanded the nomological network of callings by demonstrating its associations with novel outcomes.

Finally, although calling is predominantly thought to have positive outcomes there is research suggesting that there may also be negative outcomes. One important issue is the extent to which people with intense callings choose to remain engaged for longer in their work (and disengage to a lesser degree) than people with less intense 
callings. It is widely understood that engaging in activities out of choice is likely to lead to more positive experiences than those motivated by more external incentives (Deci \& Ryan, 2000). However, work on calling presents a mixed picture regarding whether callings are aligned with intrinsic motivation and volition (Elangovan et al., 2010) or whether callings can also involve normative or externally regulated processes, such as a sense of duty and anxiety (Bunderson \& Thompson, 2009). As an example, workaholism has been raised as a risk factor for people with callings (Duffy \& Dik, 2013). This likely depends on the context in which calling occurs. As mentioned above, could "helping industries" be at more risk for experiencing the "dark side of calling?"

In conclusion, the purpose of this dissertation was to explore the link between calling and safety within the USFS. In doing so, this study adds to both the calling and safety literatures, and aids in our understanding of the contextual variables that may lend to the conflicting results in the calling literature. Furthermore, as detailed throughout this discussion section, this study provides for a number of potential future research streams by exploring the link between calling and occupational safety. In particular, more work is needed to understand the discriminant and incremental validity of calling. Furthermore, calling scholars should examine in more detail the potential organizational factors that may potentially impact calling. Finally, although this study fails to find a relationship between calling and the safety outcomes, correlational relationships were noted that point to potentially fruitful areas for future research. 
Table 1

Responses Across Data Sources

\begin{tabular}{ccc}
\hline Data source & Forest & Number of participants \\
\hline Interviews & Phase I & 9 \\
\cline { 2 - 3 } & Phase II & 8 \\
\hline Job shadow & Phase I & 3 \\
\cline { 2 - 3 } & Phase II & 4 \\
\hline Survey & Phase I & 65 \\
\cline { 2 - 3 } & Phase II & 122 \\
\hline
\end{tabular}


Table 2

Participant demographics

Demographic Survey Respondents

\begin{tabular}{ll}
\hline Age & Mean $=46.59$ \\
& Standard Deviation $=11.90$ \\
\hline Gender & Female $=41.5 \%$ \\
& Male $=49.7 \%$ \\
& Other $=1.6 \%$ \\
& No response $=7.1 \%$ \\
\hline Hispanic/Latino & No $=66.8 \%$ \\
& Yes $=15.2 \%$ \\
& No response $=18 \%$ \\
\hline Racial Background & White $=73.2 \%$ \\
& American Indian or Alaska Native $=4.9 \%$ \\
& Asian $=3.8 \%$ \\
& Multiracial $=5.5 \%$ \\
& Other $=2.2 \%$ \\
& No response $=10.4 \%$ \\
& High school diploma or GED $=3.3 \%$, \\
& Associate Degree $(\mathrm{AA}, \mathrm{AS}$, etc. $)=9.8 \%$ \\
& Some college but no degree $=14.8 \%$ \\
& Bachelor's Degree $(\mathrm{BA}, \mathrm{BS}, \mathrm{AB}$, etc. $)=41.7 \%$ \\
& Some graduate study but no degree $=13.3 \%$ \\
& Graduate or Professional Degree $(\mathrm{MA}, \mathrm{MS}, \mathrm{PhD})=9.4 \%$ \\
& No response $=7.7 \%$ \\
\hline Education Level & Single $=9.8 \%$ \\
& Dating $=6.6 \%$ \\
& Married $=59.4 \%$ \\
& Living with Partner $=9.8 \%$ \\
& Divorced $=6.6 \%$ \\
& Widowed $=1.1 \%$ \\
& No response $=7.1 \%$ \\
\hline Relationship Status $\%$ & \\
& \\
& \\
& \\
& \\
& \\
& \\
& \\
& \\
&
\end{tabular}


CALLING AND SAFETY

Table 3

Participant job characteristics

Characteristics Survey Respondents

\begin{tabular}{|c|c|}
\hline Tenure in Forest & Mean $=10.68$ years \\
\hline Tenure at USFS & Mean $=18.66$ years \\
\hline Job Status & $\begin{array}{l}\text { Temporary Seasonal }=3.8 \% \\
\text { Permanent Seasonal }=9.8 \% \\
\text { Permanent Part-time }=2.2 \% \\
\text { Permanent Full-time }=80.3 \% \\
\text { Volunteer }=.5 \% \\
\text { No response }=3.3 \%\end{array}$ \\
\hline Occupation & $\begin{array}{l}\text { Engineering }=2.2 \% \\
\text { Recreation }=9.8 \% \\
\text { Firefighting }=14.2 \% \\
\text { Natural Resources }=29.5 \% \\
\text { Administration }=16.9 \% \\
\text { Law Enforcement }=.5 \% \\
\text { Timber Sales }=9.8 \% \\
\text { Other }=13.1 \% \\
\text { No response }=3.8 \%\end{array}$ \\
\hline Team Composition & $\begin{array}{l}\text { Works alone }=40.4 \% \\
\text { Works with others }(\text { team } / \mathrm{crew})=25.7 \% \\
\text { Works } 50 \% \text { alone } \& 50 \% \text { with others }=30.6 \% \\
\text { No response }=3.3 \%\end{array}$ \\
\hline Work Environment & $\begin{array}{l}\text { Works outdoors (in the field) }=16.9 \% \\
\text { Works indoors (in an office) }=44.8 \% \\
\text { Works } 50 \% \text { indoors and } 50 \% \text { in the field }=35.5 \% \\
\text { No response }=2.7 \%\end{array}$ \\
\hline Hours per Week & Mean $=42.47$ \\
\hline
\end{tabular}


Table 4

Means, standard deviations, and correlations of study variables

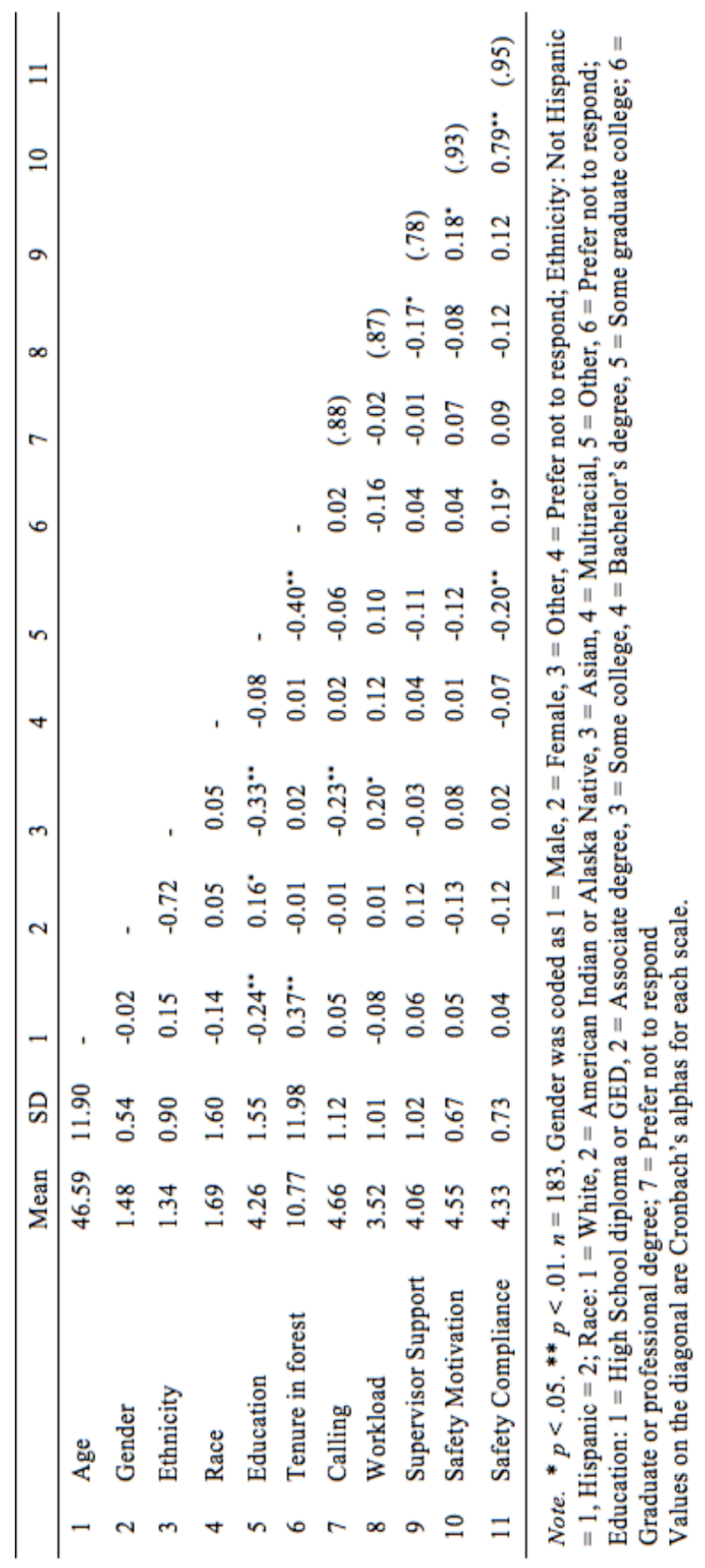


Table 5

Model summary and parameter estimates for the interaction between calling and workload predicting safety motivation.

\begin{tabular}{cccc}
\hline Model & $R$ & $R^{2}$ & MSE \\
\hline 1 & 0.16 & 0.03 & 0.47 \\
\hline
\end{tabular}

\begin{tabular}{llcccc}
\hline Model & Parameter & $B$ & Std. Error & $t$-value & $p$-value \\
\hline 1 & Intercept & 4.57 & 0.07 & 63.28 & .001 \\
\hline & Tenure & -0.01 & 0.01 & -0.32 & 0.75 \\
\hline & Calling & 0.05 & 0.05 & 0.98 & 0.33 \\
\hline & Workload & -0.07 & 0.05 & -1.21 & 0.23 \\
\hline & Calling*Workload & 0.05 & 0.05 & 1.18 & 0.24 \\
\hline
\end{tabular}

Note. $N=183 . B=$ unstandardized coefficients. All predictors are mean centered. 
Table 6

Model summary and parameter estimates for the interaction between calling and workload predicting safety compliance.

\begin{tabular}{cccc}
\hline Model & $R$ & $R^{2}$ & MSE \\
\hline 1 & 0.19 & 0.04 & 0.55 \\
\hline
\end{tabular}

\begin{tabular}{llcccc}
\hline Model & Parameter & $B$ & Std. Error & $t$-value & $p$-value \\
\hline 1 & Intercept & 4.27 & 0.08 & 54.20 & 0.001 \\
\hline & Tenure & 0.01 & 0.01 & 1.07 & 0.28 \\
\hline & Calling & 0.07 & 0.05 & 1.25 & 0.21 \\
\hline & Workload & -0.08 & 0.06 & -1.37 & 0.17 \\
\hline & Calling*Workload & 0.05 & 0.05 & 0.95 & 0.35 \\
\hline
\end{tabular}

Note. $N=183 . B=$ unstandardized coefficients. All predictors are mean centered. 
Table 7

Model summary and parameter estimates for the interaction between calling and supervisor support predicting safety motivation.

\begin{tabular}{cccc}
\hline Model & $R$ & $R^{2}$ & MSE \\
\hline 1 & 0.21 & 0.04 & 0.46 \\
\hline
\end{tabular}

\begin{tabular}{llcccc}
\hline Model & Parameter & $B$ & Std. Error & $t$-value & $p$-value \\
\hline 1 & Intercept & 4.57 & 0.07 & 63.87 & .001 \\
\hline & Tenure & -0.01 & 0.01 & -0.30 & 0.77 \\
\hline & Calling & 0.05 & 0.05 & 1.05 & 0.30 \\
\hline & SS & 0.12 & 0.05 & 2.34 & 0.02 \\
\hline & Calling*SS & -0.05 & 0.05 & -1.07 & 0.29
\end{tabular}

Note. $N=183 . B=$ unstandardized coefficients. $S S=$ Supervisor Support. All predictors are mean centered. 
Table 8

Model summary and parameter estimates for the interaction between calling and supervisor support predicting safety compliance.

\begin{tabular}{cccc}
\hline Model & $R$ & $R^{2}$ & MSE \\
\hline 1 & 0.19 & 0.04 & 0.56
\end{tabular}

\begin{tabular}{llcccc}
\hline Model & Parameter & $B$ & Std. Error & $t$-value & $p$-value \\
\hline 1 & Intercept & 4.27 & 0.08 & 54.13 & .001 \\
\hline & Tenure & 0.01 & 0.01 & 1.15 & 0.25 \\
\hline & Calling & 0.07 & 0.05 & 1.30 & 0.20 \\
\hline & SS & 0.09 & 0.06 & 1.58 & 0.12 \\
\hline & Calling*SS & -0.03 & 0.05 & -0.62 & 0.53 \\
\hline
\end{tabular}

Note. $N=183 . B=$ unstandardized coefficients. $S S=$ Supervisor Support.

All predictors are mean centered. 
Table 9

Model summary and parameter estimates for the three-way interaction between calling, workload, and supervisor support predicting safety motivation.

\begin{tabular}{cccc}
\hline Model & $R$ & $R^{2}$ & MSE \\
\hline 3 & 0.31 & 0.10 & .44 \\
\hline
\end{tabular}

\begin{tabular}{llcccc}
\hline Model & Parameter & $B$ & Std. Error & t-value & $p$-value \\
\hline 1 & Intercept & 4.59 & 0.07 & 65.02 & 0.001 \\
\hline Tenure & -0.01 & 0.01 & -0.29 & 0.78 \\
\hline Calling & 0.05 & 0.04 & 1.01 & 0.31 \\
\hline Supervisor Support & 0.10 & 0.05 & 1.91 & 0.06 \\
\hline Workload & -0.06 & 0.06 & -1.06 & 0.29 \\
\hline Calling*Workload & 0.07 & 0.05 & 1.44 & 0.15 \\
\hline Calling*SS & -0.04 & 0.05 & -0.83 & 0.41 \\
\hline Workload*SS & 0.14 & 0.07 & 2.04 & 0.04 \\
\hline Calling*Workload*SS & -0.04 & 0.05 & -0.79 & 0.43 \\
\hline
\end{tabular}

Note. $N=183 . B=$ unstandardized coefficients. $S S=$ Supervisor Support. All predictors are mean centered. 
Table 10

Model summary and parameter estimates for the three-way interaction between calling, workload, and supervisor support predicting safety compliance.

\begin{tabular}{cccc}
\hline Model & $R$ & $R^{2}$ & MSE \\
\hline 3 & 0.29 & 0.08 & 0.54 \\
\hline
\end{tabular}

\begin{tabular}{llcccc}
\hline Model & Parameter & $B$ & Std. Error & $t$-value & $p$-value \\
\hline 3 & Intercept & 4.30 & 0.08 & 55.60 & 0.001 \\
\hline & Tenure & 0.01 & 0.01 & 1.11 & 0.27 \\
\hline Calling & 0.06 & 0.05 & 1.24 & 0.22 \\
\hline Supervisor Support & 0.07 & 0.06 & 1.21 & 0.23 \\
\hline Workload & -0.08 & 0.06 & -1.32 & 0.19 \\
\hline Calling*Workload & 0.07 & 0.06 & 1.18 & 0.24 \\
\hline Calling*SS & -0.03 & 0.05 & -0.48 & 0.64 \\
\hline Workload*SS & 0.14 & 0.07 & 2.10 & 0.04 \\
\hline Calling*Workload*SS & -0.02 & 0.05 & -0.43 & 0.68
\end{tabular}

Note. $N=183 . B=$ unstandardized coefficients. $S S=$ Supervisor Support. All predictors are mean centered. 
Figure 1

\section{Conceptual Model}

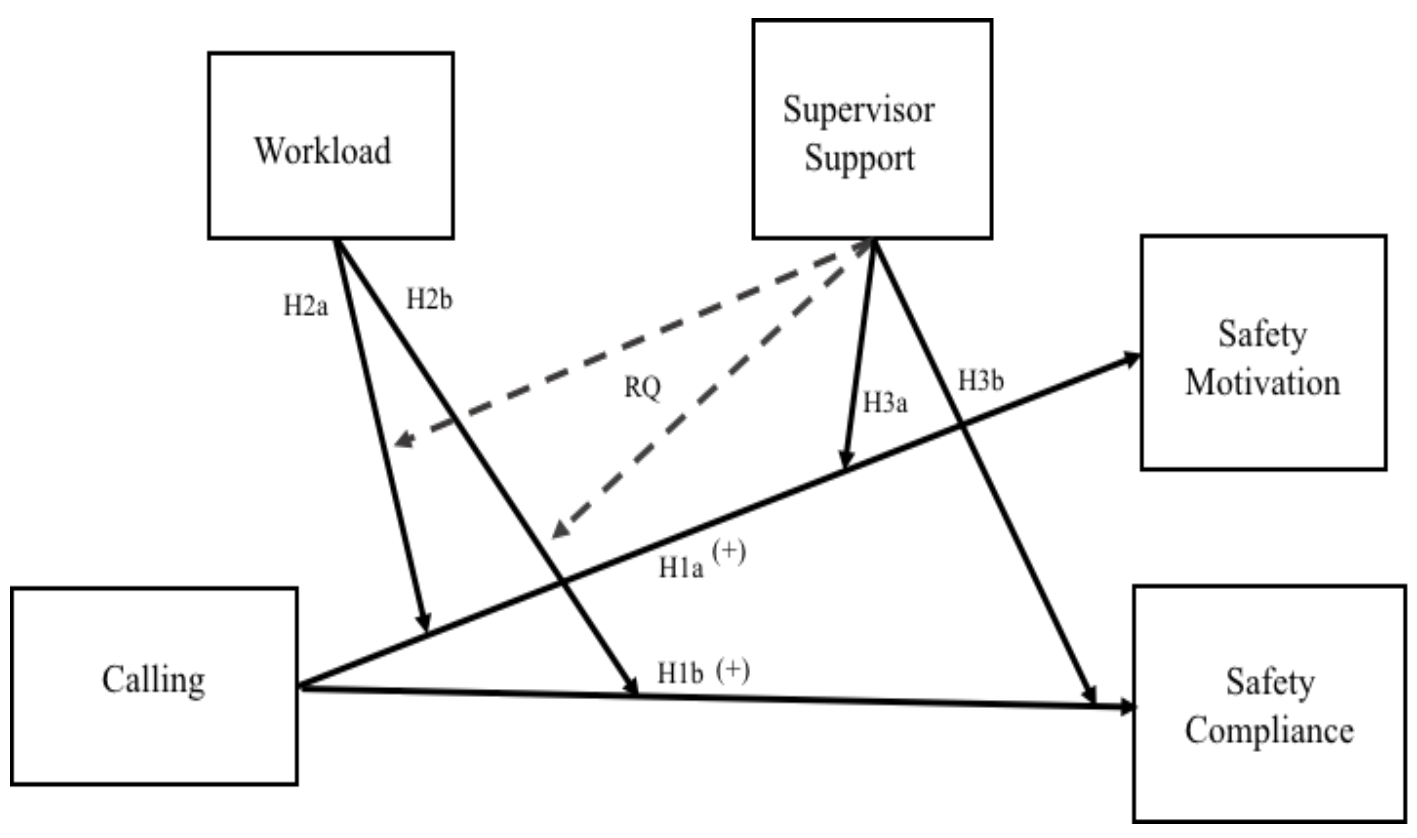




\section{References}

Aguinis, H., Edwards, J. R., \& Bradley, K. J. (2017). Improving our understanding of moderation and mediation in strategic management research. Organizational Research Methods, 20, 665-685.

Allan, B. A., \& Duffy, R. D. (2014). Calling, goals, and life satisfaction: A moderated mediation model. Journal of Career Assessment, 22, 451-464.

Amabile, T. M., Hill, K. G., Hennessey, B. A., \& Tighe, E. M. (1994). The Work Preference Inventory: Assessing intrinsic and extrinsic motivational orientations. Journal of Personality and Social psychology, 66, 950-967.

Ashforth, B. E., \& Mael, F. (1989). Social identity theory and the organization. Academy of Management Review, 14, 20-39.

Bakker, A. B. (2015). A Job Demands-Resources approach to public service motivation. Public Administration Review, 75, 723-732.

Bakker, A. B., \& Demerouti, E. (2007). The job demands-resources model: State of the art. Journal of Managerial Psychology, 22, 309-328.

Bakker, A. B., Demerouti, E., \& Schaufeli, W. B. (2005). The crossover of burnout and work engagement among working couples. Human Relations, 58, 661-689.

Bakker, A. B., Hakanen, J. J., Demerouti, E., \& Xanthopoulou, D. (2007). Job resources boost work engagement, particularly when job demands are high. Journal of Educational Psychology, 99, 274-284.

Barling, J., Kelloway, E. K., \& Iverson, R. D. (2003). High-quality work, job satisfaction, and occupational injuries. Journal of Applied Psychology, 88, 276-283. 
Bellah, R. N., Madsen, R., Sullivan, W. M., Swidler, A., \& Tipton, S. M. (1985). Habits of the heart: Individualism and commitment in American life. New York, NY: Harper \& Row.

Berg, J. M., Grant, A. M., \& Johnson, V. (2010). When callings are calling: Crafting work and leisure in pursuit of unanswered occupational callings. Organization Science, 21, 973-994.

Beus, J. M., Bergman, M. E., \& Payne, S. C. (2010). The influence of organizational tenure on safety climate strength: A first look. Accident Analysis \& Prevention, 42, 1431-1437.

Beus, J. M., Dhanani, L. Y., \& McCord, M. A. (2015). A meta-analysis of personality and workplace safety: Addressing unanswered questions. Journal of Applied Psychology, 100, 481-498.

Beus, J. M., Payne, S. C., Bergman, M. E., \& Arthur, W., Jr. (2010). Safety climate and injuries: An examination of theoretical and empirical relationships. Journal of Applied Psychology, 95, 713-727.

Biron, C., Brun, J. P., Ivers, H., \& Cooper, C. (2006). At work but ill: Psychosocial work environment and well-being determinants of presenteeism propensity. Journal of Public Mental Health, 5, 26-37.

Blau, P. M. (1964). Exchange and Power in Social Life. New York: John Wiley and Sons.

Borman, W. C., \& Motowidlo, S. M. (1993). Expanding the criterion domain to include elements of contextual performance. In N. Schmitt and W. C. Borman (Eds.), 
Personnel selection in organizations (pp. 71-98). San Francisco: Jossey-Bass.

Bott, E. M., \& Duffy, R. D. (2015). A two-wave longitudinal study of career calling among undergraduates testing for predictors. Journal of Career Assessment, 23, 250-264.

Bowling, N. A., Alarcon, G. M., Bragg, C. B., \& Hartman, M. J. (2015). A meta-analytic examination of the potential correlates and consequences of workload. Work \& Stress, 29, 95-113.

Bowling, N. A., \& Kirkendall, C. (2012). Workload: A review of potential causes, consequences, and interventions. In J. Houdmont, S. Leka, \& R. Sinclair (Eds.), Contemporary occupational health psychology: Global perspectives on research and practice (Vol. 2, pp. 221-238). Chichester: Wiley-Blackwell.

Brown, K. A., Willis, P. G., \& Prussia, G. E. (2000). Predicting safe employee behavior in the steel industry: Development and test of a sociotechnical model. Journal of Operations Management, 18, 445- 465.

Bunderson, J. S., \& Thompson, J. A. (2009). The call of the wild: Zookeepers, callings, and the dual edges of deeply meaningful work. Administrative Science Quarterly, $54,32-57$.

Burke, M. J., \& Signal, S. M. (2010). Workplace safety: A multilevel, interdisciplinary perspective. In H. Liao, J. J. Martocchio, \& A. Joshi (Eds.), Research in personnel and human resource management (Vol. 29, pp. 1-47). Emerald Group Publishing Limited.

Carayon, P., \& Gürses, A. P. (2005). A human factors engineering conceptual framework 
of nursing workload and patient safety in intensive care units. Intensive and Critical Care Nursing, 21, 284-301.

Cardador, M. T., \& Caza, B. B. (2012). Relational and identity perspectives on healthy versus unhealthy pursuit of callings. Journal of Career Assessment, 20, 338-353.

Cardador, M. T., Dane, E., \& Pratt, M. G. (2011). Linking calling orientations to organizational attachment via organizational instrumentality. Journal of Vocational Behavior, 79, 367-378.

Chen, P. Y., \& Spector, P. E. (1991). Negative affectivity as the underlying cause of correlations between stressors and strains. Journal of Applied Psychology, 76, $398-407$.

Christian, M. S., Bradley, J. C., Wallace, J. C., \& Burke, M. J. (2009). Workplace safety: A meta-analysis of the roles of person and situation factors. Journal of Applied Psychology, 94, 1103-1127.

Clarke, S. (2006). The relationship between safety climate and safety performance: A meta-analytic review. Journal of Occupational Health Psychology, 11, 315-327.

Clarke, S., \& Robertson, I. (2005). A meta-analytic review of the Big Five personality factors and accident involvement in occupational and non-occupational settings. Journal of Occupational and Organizational Psychology, 78, 355-376.

Cohen, S., Mermelstein, R., Kamarck, T., \& Hoberman, H. M. (1985). Measuring the functional components of social support. In Social support: Theory, research and applications (p. 73-94). Netherlands: Springer.

Cohen, A., Smith, M. J., \& Anger, W. (1979). Self-protective measures against 
workplace hazards. Journal of Safety Research, 11, 121-131.

Colquitt, J. A., Scott, B. A., Rodell, J. B., Long, D. M., Zapata, C. P., Conlon, D. E., \& Wesson, M. J. (2013). Justice at the millennium, a decade later: A meta-analytic test of social exchange and affect-based perspectives. Journal of Applied Psychology, 98, 199-236.

Conway, N., Clinton, M., Sturges, J., \& Budjanovcanin, A. (2015). Using selfdetermination theory to understand the relationship between calling enactment and daily well-being. Journal of Organizational Behavior, 36, 1114-1131.

Cook, T. D., \& Campbell, D. T. (1979). Quasi-experimentation: Design and analysis for field settings. Boston: Houghton Mifflin.

Cropanzano, R., Byrne, Z. S., Bobocel, D. R., \& Rupp, D. E. (2001). Moral virtues, fairness heuristics, social entities, and other denizens of organizational justice. Journal of Vocational Behavior, 58, 164-209.

Cropanzano, R., \& Mitchell, M. S. (2005). Social exchange theory: An interdisciplinary review. Journal of Management, 31, 874-900.

Csikszentmihalyi, M. (1990). Flow: The psychology of optimal performance. New York: Cambridge University Press.

Daniels, K., \& Guppy, A. (1997). Stressors, locus of control, and social support as consequences of affective psychological well-being. Journal of Occupational Health Psychology, 2, 156-174.

Davidson, J. C., \& Caddell, D. P. (1994). Religion and the meaning of work. Journal for the Scientific Study of Religion, 33, 135-147. 
Demerouti, E., Bakker, A. B., Nachreiner, F., \& Schaufeli, W. B. (2001). The job demands-resources model of burnout. Journal of Applied Psychology, 86, 499512.

Demsky, C. \& Fritz, C. (2015). Relationships between work experiences and the occupational safety, health, \& well-being of USDA Forest Service Region 3 employees: Technical Report for the United States Department of Agriculture Forest Service.

DeJoy, D. M., Schaffer, B. S., Wilson, M. G., Vandenberg, R. J., \& Butts, M. M. (2004). Creating safer workplaces: Assessing the determinants and role of safety climate. Journal of Safety Research, 35, 81-90.

Dik, B. J., \& Duffy, R. D. (2009). Calling and vocation at work: Definitions and prospects for research and practice. The Counseling Psychologist, 37, 424-450.

Dik, B. J., Duffy, R. D., \& Eldridge, B. M. (2009). Calling and vocation in career counseling: Recommendations for promoting meaningful work. Professional Psychology: Research and Practice, 40, 625-632.

Dobrow, S. R. (2006). Having a calling. A longitudinal study of young musicians. Retrieved from Dissertations and Theses Database (AAT 3217715).

Dobrow, S. R., \& Heller, D. (2015). Follow your heart or your head? A longitudinal study of the facilitating role of calling and ability in the pursuit of a challenging career. Journal of Applied Psychology, 100, 695-712.

Dobrow, S. R., \& Tosti-Kharas, J. (2011). Calling: The development of a scale measure. Personnel Psychology, 64, 1001-1049. 
Douglass, R. P., \& Duffy, R. D. (2015). Calling and career adaptability among undergraduate students. Journal of Vocational Behavior, 86, 58-65.

Duffy, R. D., Allan, B. A., Autin, K. L., \& Douglass, R. P. (2014). Living a calling and work well-being: A longitudinal study. Journal of Counseling Psychology, 61, 605-615.

Duffy, R. D., \& Blustein, D. L. (2005). The relationship between spirituality, religiousness, and career adaptability. Journal of Vocational Behavior, 67, 429440.

Duffy, R. D., Bott, E. M., Allan, B. A., \& Autin, K. L. (2015). Calling among the unemployed: Examining prevalence and links to coping with job loss. The Journal of Positive Psychology, 10, 332-345.

Duffy, R. D., Bott, E. M., Allan, B. A., Torrey, C. L., \& Dik, B. J. (2012). Perceiving a calling, living a calling, and job satisfaction: Testing a moderated, multiple mediator model. Journal of Counseling Psychology, 59, 50-59.

Duffy, R. D., \& Dik, B. J. (2013). Research on calling: What have we learned and where are we going? Journal of Vocational Behavior, 83, 428-436.

Duffy, R. D., Dik, B. J., \& Steger, M. F. (2011). Calling and work related outcomes: Career commitment as a mediator. Journal of Vocational Behavior, 78, 210-218.

Duffy, R. D., Manuel, R. S., Borges, N. J., \& Bott, E. M. (2011). Calling, vocational development, and well-being: A longitudinal study of medical students. Journal of Vocational Behavior, 79, 361-366.

Duffy, R. D., \& Sedlacek, W. E. (2007). The presence of and search for a calling: 
Connections to career development. Journal of Vocational Behavior, 70, 590601.

Eisenberger, R., Armeli, S., Rexwinkel, B., Lynch, P. D., \& Rhoades, L. (2001). Reciprocation of perceived organizational support. Journal of Applied Psychology, 86, 42-51.

Eisenberger, R., Huntington, R., Hutchison, S., \& Sowa, D. (1986). Perceived organizational support. Journal of Applied Psychology, 71, 500-507.

Elangovan, A. R., Pinder, C. C., \& McLean, M. (2010). Callings and organizational behavior. Journal of Vocational Behavior, 76, 428-440.

Emerson, R. M. (1976). Social exchange theory. Annual Review of Sociology, 2, 335-362.

Faul, F., Erdfelder, E., Buchner, A., \& Lang, A.-G. (2009). Statistical power analyses using $\mathrm{G}^{*}$ Power 3.1: Tests for correlation and regression analyses. Behavior Research Methods, 41, 1149-1160.

Friedman, I. A. (2002). Burnout in school principals: Role related antecedents. Social Psychology of Education, 5, 229-251.

Fritz, C., \& Sonnentag, S. (2006). Recovery, well-being, and performance-related outcomes: The role of workload and vacation experiences. Journal of Applied Psychology, 91, 936-945.

Frone, M. R. (1998). Predictors of work injuries among employed adolescents. Journal of Applied Psychology, 83, 565.

Ganster, D. C., Fox, M. L., \& Dwyer, D. J. (2001). Explaining employees' health care costs: A prospective examination of stressful job demands, personal control, and 
physiological reactivity. Journal of Applied Psychology, 86, 954-964.

Glaser, B. S., \& Strauss, A. (1967). The discovery of grounded theory. Strategies for qualitative research. London: Weidenfeld and Nicolson.

Goldenhar, L. M., Williams, L. J., \& Swanson, N. G. (2003). Modeling relationships between job stressors and injury and near-miss outcomes for construction labourers. Work \& Stress, 17, 218-240

Gouldner, A. W. (1960). The norm of reciprocity: A preliminary statement. American Sociological Review, 25, 161-178.

Grant, A. M. (2007). Relational job design and the motivation to make a prosocial difference. Academy of Management Review, 32, 393-417.

Grant, A. M. (2008). The significance of task significance: Job performance effects, relational mechanisms, and boundary conditions. Journal of Applied Psychology, 93, 108-124.

Grant, A. M., Fried, Y., Parker, S. K., \& Frese, M. (2010). Putting job design in context: Introduction to the special issue. Journal of Organizational Behavior, 31, 145157.

Green, S. G., Anderson, S. E., \& Shivers, S. L. (1996). Demographic and organizational influences on leader-member exchange and related work attitudes. Organizational Behavior and Human Decision Processes, 66, 203-214.

Griffin, M. A., \& Neal, A. (2000). Perceptions of safety at work: A framework for linking safety climate to safety performance, knowledge, and motivation. Journal of Occupational Health Psychology, 5, 347-358. 
Hammer, L. B., Johnson, R. C., Crain, T. L., Bodner, T., Kossek, E. E., Davis, K. D., ... \& Berkman, L. (2016). Intervention effects on safety compliance and citizenship behaviors: Evidence from the Work, Family, and Health Study. Journal of Applied Psychology, 101, 190-208.

Hall, D. T., \& Chandler, D. E. (2005). Psychological success: When the career is a calling. Journal of Organizational Behavior, 26, 155-176.

Hansez, I., \& Chmiel, N. (2010). Safety behavior: Job demands, job resources, and perceived management commitment to safety. Journal of Occupational Health Psychology, 15, 267-278.

Hayes, B.E., Peranda, J., Smecko, T. \& Trask, J. (1998). Measuring perceptions of workplace safety: Development and validation of the workplace safety scale, Journal of Safety Research, 29,145-161.

Higgins, E. T. (1987). Self-discrepancy: A theory relating self and affect. Psychological Review, 94, 319-340.

Hirschi, A. (2012). Callings and work engagement: Moderated mediation model of work meaningfulness, occupational identity, and occupational self-efficacy. Journal of Counseling Psychology, 59, 479-485.

Hockey, G. R. J. (1997). Compensatory control in the regulation of human performance under stress and high workload: A cognitive-energetical framework. Biological psychology, 45(1), 73-93.

Hofmann, D. A., Burke, M. J., \& Zohar, D. (2017). 100 years of occupational safety research: From basic protections and work analysis to a multilevel view of 
workplace safety and risk. Journal of Applied Psychology, 102, 375-388.

Hofmann, D. A., \& Morgeson, F. P. (1999). Safety-related behavior as a social exchange: The role of perceived organizational support and leader-member exchange. Journal of Applied Psychology, 84, 286 -296.

Hofmann, D. A., \& Stetzer, A. (1996). A cross-level investigation of factors influencing unsafe behaviors and accidents. Personnel Psychology, 49, 307-339.

Holden, R. J., Scanlon, M. C., Patel, N. R., Kaushal, R., Escoto, K. H., Brown, R. L., ... \& Karsh, B. T. (2011). A human factors framework and study of the effect of nursing workload on patient safety and employee quality of working life. $B M J$ Quality \& Safety, 20, 15-24.

Hollenbeck, J. R., \& Wright, P. M. (2017). Harking, sharking, and tharking: Making the case for post hoc analysis of scientific data. Journal of Management, 1, 5-18.

Hopkins, K. M. (2002). Interactions of gender and race in workers' help seeking for personal/family problems perceptions of supervisor support and intervention. The Journal of Applied Behavioral Science, 38, 156-176.

House, J. S. (1981). Work stress and social support. Reading, MA: Addison-Wesley.

Huang, Y. H., Chen, P. Y., Krauss, A. D., \& Rogers, D. A. (2004). Quality of the execution of corporate safety policies and employee safety outcomes: Assessing the moderating role of supervisor safety support and the mediating role of employee safety control. Journal of Business and Psychology, 18, 483-506.

Hughes, E. C. (1958). Men and their work. Glencoe, IL: Free Press.

Ilies, R., Dimotakis, N., \& De Pater, I. E. (2010). Psychological and physiological 
reactions to high workloads: Implications for well-being. Personnel

Psychology, 63, 407-436.

Inness, M., Turner, N., Barling, J., \& Stride, C. B. (2010). Transformational leadership and employee safety performance: A within-person, between-jobs design. Journal of Occupational Health Psychology, 15, 279-290.

Iverson, R. D., \& Erwin, P. J. (1997). Predicting occupational injury: The role of affectivity. Journal of Occupational and Organizational Psychology, 70, 113-128.

Jiang, L., Yu, G., Li, Y., \& Li, F. (2010). Perceived colleagues' safety knowledge/behavior and safety performance: Safety climate as a moderator in a multilevel study. Accident Analysis \& Prevention, 42, 1468-1476.

Janicak, C. A. (1998). Fall-related deaths in the construction industry. Journal of Safety Research, 29, 35-42.

Janssens, M., Brett, J. M., \& Smith, F. J. (1995). Confirmatory cross-cultural research: Testing the viability of a corporation-wide safety policy. Academy of Management Journal, 38, 364-382.

Janssen, P. P. M., Bakker, A. B., \& de Jonge, J. (2001). A test and refinement of the demand control-support model in the construction industry. International Journal of Stress Management, 8, 315-332.

Jepsen, D. M., \& Rodwell, J. J. (2010). A social exchange model of the employment relationship based on keeping tally of the psychological contract. Employment Relations Record, 10, 20-45.

Joshi, A. W., \& Randall, S. (2001). The indirect effects of organizational controls on 
salesperson performance and customer orientation. Journal of Business Research, 54, 1-9.

Hayes A. F. (2013). Introduction to mediation, moderation, and conditional process analysis: A regression-based approach. New York: Guilford Press.

Kahn, W. (1990). Psychological conditions of personal engagement and disengagement at work. Academy of Management Journal, 33, 692-724.

Kaminsky, S. E., \& Behrend, T. S. (2015). Career choice and calling integrating calling and social cognitive career theory. Journal of Career Assessment, 23, 383-398.

Kaplan, S., \& Tetrick, L. E. (2011). Workplace safety and accidents: An industrial and organizational psychology perspective. In S. Zedeck (Ed.), APA handbook of Industrial and Organizational Psychology (Vol. 1, pp. 455-472). Washington, DC: American Psychological Association.

Karasek Jr, R. A. (1979). Job demands, job decision latitude, and mental strain: Implications for job redesign. Administrative Science Quarterly, 2, 285-308.

Kawada, T., \& Otsuka, T. (2011). Relationship between job stress, occupational position and job satisfaction using a brief job stress questionnaire (BJSQ). Work, 40, 393399.

Kinicki, A. J., \& Vecchio, R. P. (1994). Influences on the quality of supervisorsubordinate relations: The role of time-pressure, organizational commitment, and locus of control. Journal of Organizational Behavior, 15, 75-82.

Konovsky, M. A., \& Pugh, S. D. (1994). Citizenship behavior and social exchange. Academy of Management Journal, 37, 656-669. 
Latham, G. P., \& Pinder, C. C. (2005). Work motivation theory and research at the dawn of the twenty-first century. Annual Review Psychology, 56, 485-516.

Lavelle, J. J., Rupp, D. E., \& Brockner, J. (2007). Taking a multifoci approach to the study of justice, social exchange, and citizenship behavior: The target similarity model. Journal of Management, 33, 841-866.

Leigh, J. P. (2011). Economic burden of occupational injury and illness in the United States. Millbank Quarterly 89, 728-772.

Leiter, M. P., \& Harvie, P. (1997). Correspondence of supervisor and subordinate perspectives during major organizational change. Journal of Occupational Health Psychology, 2, 343-352.

LePine, J. A., Podsakoff, N. P., \& LePine, M. A. (2005). A meta-analytic test of the challenge stressor-hindrance stressor framework: An explanation for inconsistent relationships among stressors and performance. Academy of Management Journal, 48, 764-775.

Levinson, H. (1965). Reciprocation: The relationship between man and organization. Administrative Science Quarterly, 9, 370-390.

Li, F., Jiang, L., Yao, X., \& Li, Y. (2013). Job demands, job resources and safety outcomes: The roles of emotional exhaustion and safety compliance. Accident Analysis \& Prevention, 51, 243-251.

Lim, V. K. (1997). Moderating effects of work-based support on the relationship between job insecurity and its consequences. Work \& Stress, 11, 251-266.

Lips-Wiersma, M. (2002). The influence of spiritual "meaning-making” on career 
behavior. Journal of Management Development, 21, 497-520.

Luthans, F. (2002). The need for and meaning of positive organizational behavior. Journal of Organizational Behavior, 23, 695-706.

Mael, F. A., \& Ashforth, B. E. (1995). Loyal from day one: Biodata, organizational identification, and turnover among newcomers. Personnel Psychology, 48, 309333.

Maierhofer, N. I., Griffin, M. A., \& Sheehan, M. (2000). Linking manager values and behavior with employee values and behavior: A study of values and safety in the hairdressing industry. Journal of Occupational Health Psychology, 5, 417-427.

Maslach, C., \& Jackson, S. E. (1981). MBI: Maslach burnout inventory. Palo Alto, CA, 1(2), 49-78.

Meyer, J. P., \& Allen, N. J. (1991). A three-component conceptualization of organizational commitment. Human Resource Management Review, 1, 61-89.

Miles, D. E., Borman, W. E., Spector, P. E., \& Fox, S. (2002). Building an integrative model of extra role work behaviors: A comparison of counterproductive work behavior with organizational citizenship behavior. International Journal of Selection and Assessment, 10, 51-57.

Miner, J. B. (1984). The validity and usefulness of theories in an emerging organizational science. Academy of Management Review, 9, 296-306.

Miner, J. B. (2003). The rated importance, scientific validity, and practical usefulness of organizational behavior theories: A quantitative review. Academy of Management Learning \& Education, 2, 250-268. 
Morgeson, F. P., \& Humphrey, S. E. (2006). The Work Design Questionnaire (WDQ): Developing and validating a comprehensive measure for assessing job design and the nature of work. Journal of Applied Psychology, 91, 1321-1339.

Muhammad, A. H., \& Hamdy, H. I. (2005). Burnout, supervisory support, and work outcomes: A study from an Arabic cultural perspective. International Journal of Commerce and Management, 15, 230-243.

Mullen, J., Kelloway, E. K., \& Teed, M. (2011). Inconsistent style of leadership as a predictor of safety behaviour. Work \& Stress, 25, 41-54.

Nahrgang, J. D., Morgeson, F. P., \& Hofmann, D. A. (2011). Safety at work: A metaanalytic investigation of the link between job demands, job resources, burnout, engagement, and safety outcomes. Journal of Applied Psychology, 96, 71-94.

Neal, A., \& Griffin, M. A. (2002). Safety climate and safety behaviour. Australian Journal of Management, 27, 67-75.

Neal, A., \& Griffin, M. A. (2004). Safety climate and safety at work. In J. Barling \& M. R. Frone (Eds.), The Psychology of Workplace Safety (pp. 15-34). Washington, DC: American Psychological Association.

Neal, A., \& Griffin, M. A. (2006). A study of the lagged relationships among safety climate, safety motivation, safety behavior, and accidents at the individual and group levels. Journal of Applied Psychology, 91, 946-953.

Neal, A., Griffin, M. A., \& Hart, P. M. (2000). The impact of organizational climate on safety climate and individual behavior. Safety Science, 34, 99-109.

Newnam, S., Griffin, M. A., \& Mason, C. (2008). Safety in work vehicles: A multilevel 
study linking safety values and individual predictors to work-related driving crashes. Journal of Applied Psychology, 93, 632-644.

Oregon Fatality Assessment and Control Evaluation (OR-FACE). OR-FACE Annual Reports. Retrieved 2/23/16 from http://www.ohsu.edu/xd/research/centersinstitutes/oregon-institute-occupational-health-sciences/outreach/or-face/.

Parasuraman, S., \& Purohit, Y. S. (2000). Distress and boredom among orchestra musicians: The two faces of stress. Journal of Occupational Health Psychology, $5,74-83$.

Park, J., Sohn, Y. W., \& Ha, Y. J. (2016). South Korean salespersons' calling, job performance, and organizational citizenship behavior: The mediating role of occupational self-efficacy. Journal of Career Assessment, 24, 415-428.

Peterson, C., Park, N., Hall, N., \& Seligman, M. E. (2009). Zest and work. Journal of Organizational Behavior, 30, 161-172.

Porter, G. (1996). Organizational impact of workaholism: Suggestions for researching the negative outcomes of excessive work. Journal of Occupational Health Psychology, 1, 70-84.

Posig, M., \& Kickul, J. (2003). Extending our understanding of burnout: Test of an integrated model in nonservice occupations. Journal of Occupational Health Psychology, 8, 3-19.

Posner, B. Z. (2010). Another look at the impact of personal and organizational values congruency. Journal of Business Ethics, 97, 535-541.

Praskova, A., Creed, P. A., \& Hood, M. (2015). The development and initial validation of 
a career calling scale for emerging adults. Journal of Career Assessment, 23, 91106.

Pratt, M. G. (1989). To be or not to be? Central questions in organizational identification. In D. A. Whetten \& P. C. Godfrey (Eds.), Identity in Organizations: Building Theory Through Conversations, pg. 171-208. Thousand Oaks: Sage.

Pratt, M. G., \& Ashforth, B. E. (2003). Fostering meaningfulness in working and at work. Positive organizational scholarship: Foundations of a new discipline, 309327.

Probst, T. M. (2004). Safety and insecurity: Exploring the moderating effect of organizational safety climate. Journal of Occupational Health Psychology, 9, 310.

Probst, T. M., \& Brubaker, T. L. (2001). The effects of job insecurity on employee safety outcomes: cross-sectional and longitudinal explorations. Journal of Occupational Health Psychology, 6, 139-159.

Raja, U., Johns, G., \& Ntalianis, F. (2004). The impact of personality on psychological contracts. Academy of Management Journal, 47, 350-367.

Rawat, A., \& Nadavulakere, S. (2015). Examining the outcomes of having a calling: Does context matter? Journal of Business and Psychology, 30, 499-512.

Restubog, S. L. D., Hornsey, M. J., Bordia, P., \& Esposo, S. R. (2008). Effects of psychological contract breach on organizational citizenship behaviour: Insights from the group value model. Journal of Management Studies, 45(8), 1377-1400.

Rhoades, L., \& Eisenberger, R. (2002). Perceived organizational support: A review of the 
literature. Journal of Applied Psychology, 87, 698-714.

Rizzo, J. R., House, R. J., \& Lirtzman, S. I. (1970). Role conflict and ambiguity in complex organizations. Administrative Science Quarterly, 150-163.

Robinson, S. L. (1996). Trust and breach of the psychological contract. Administrative Science Quarterly, 574-599.

Robinson, S. L., \& Rousseau, D. M. (1994). Violating the psychological contract: Not the exception but the norm. Journal of Organizational Behavior, 15, 245-259.

Rousseau, D. (1995). Psychological contracts in organizations: Understanding written and unwritten agreements. Thousand Oaks, CA: Sage Publications.

Rousseau, D. M. (1998). The 'problem' of the psychological contract considered. Journal of Organizational Behavior, 19, 665-671.

Rousseau, D. M., \& McLean Parks, J. (1993). The contracts of individuals and organizations. Research in Organizational Behavior, 15, 1-43.

Rupp, D. E., \& Cropanzano, R. (2002). The mediating effects of social exchange relationships in predicting workplace outcomes from multifoci organizational justice. Organizational Behavior and Human Decision Processes, 89, 925-946.

Rydstedt, L. W., Ferrie, J., \& Head, J. (2006). Is there support for curvilinear relationships between psychosocial work characteristics and mental well-being? Cross-sectional and long-term data from the Whitehall II study. Work \& Stress, 20, 6-20.

Seligman, M. E., \& Csikszentmihalyi, M. (2000). Special issue on happiness, excellence, and optimal human functioning. American Psychologist, 55, 5-183. 
Seo, D. C., Torabi, M. R., Blair, E. H., \& Ellis, N. T. (2004). A cross-validation of safety climate scale using confirmatory factor analytic approach. Journal of Safety Research, 35, 427-445.

Serow, R. C. (1994). Called to teach: A study of highly motivated preservice teachers. Journal of Research \& Development in Education, 27, 65-72.

Serow, R. C., Eaker, D., \& Ciechalski, J. (1992). Calling, service and legitimacy: Professional orientations and career commitment among prospective teachers. Journal of Research and Development in Education, 25, 136-141.

Shore, L. M., Coyle-Shapiro, J. A. M., Chen, X. P., \& Tetrick, L. E. (2009). Social exchange in work settings: Content, process, and mixed models. Management and Organization Review, 5, 289-302.

Siegrist, J. (1996). Adverse health effects of high-effort/low-reward conditions. Journal of Occupational Health Psychology, 1, 27-41.

Siu, O. L., Phillips, D. R., \& Leung, T. W. (2003). Age differences in safety attitudes and safety performance in Hong Kong construction workers. Journal of Safety Research, 34, 199-205.

Smith, B. W., Dalen, J., Wiggins, K., Tooley, E., Christopher, P., \& Bernard, J. (2008). The brief resilience scale: Assessing the ability to bounce back. International Journal of Behavioral Medicine, 15, 194-200.

Spector, P. E. (2006). Method variance in organizational research truth or urban legend? Organizational Research Methods, 9, 221-232.

Spector, P. E., \& Brannick, M. T. (2011). Methodological urban legends: The misuse of 
statistical control variables. Organizational Research Methods, 14, 287-305.

Spector, P. E., \& Jex, S. M. (1998). Development of four self-report measures of job stressors and strain: Interpersonal conflict at work scale, organizational constraints scale, quantitative workload inventory, and physical symptoms inventory. Journal of Occupational Health Psychology, 3, 356-367.

Spence, J. T., \& Robbins, A. S. (1992). Workaholism: Definition, measurement, and preliminary results. Journal of Personality Assessment, 58, 160-178.

Soper, D.S. (2016). A-priori Sample Size Calculator for Multiple Regression [Software]. Available from http://www.danielsoper.com/statcalc

Steger, M. F., Dik, B. J., \& Duffy, R. D. (2012). Measuring meaningful work: The work and meaning inventory (WAMI). Journal of Career Assessment, 20, 322-337.

Steger, M. F., Pickering, N. K., Shin, J. Y., \& Dik, B. J. (2010). Calling in work secular or sacred? Journal of Career Assessment, 18, 82-96.

Sutton, R. I., \& Rafaeli, A. (1987). Characteristics of work stations as potential occupational stressors. Academy of Management Journal, 30, 260-276.

Taris, T. W. (2006). Is there a relationship between burnout and objective performance? A critical review of 16 studies. Work \& Stress, 20, 316-334.

Tepper, B. (1994). Investigation of general and program-specific attitudes toward corporate drug-testing policies. Journal of Applied Psychology, 79, 392-401.

Tetrick, L. E., \& Peiró, J. M. (2016). Health and safety: Prevention and promotion. In M. Grawitch and D.W. Ballard, (Eds.). The psychologically healthy workplace: Building a win-win environment for organizations and employees. (pp. 199-229). 
Washington, DC, US: American Psychological Association

Thompson, B. M., Brough, P. A., \& Schmidt, H. (2006). Supervisor and subordinate work-family values: Does similarity make a difference? International Journal of Stress Management, 13, 45-63.

Thompson, J. A., \& Bunderson, J. S. (2003). Violations of principle: Ideological currency in the psychological contract. Academy of Management Review, 28, 571-586.

Torp, S., \& Grøgaard, J. B. (2009). The influence of individual and contextual work factors on workers' compliance with health and safety routines. Applied Ergonomics, 40, 185-193.

Treadgold, R. (1999). Transcendent vocations: Their relationship to stress, depression, and clarity of self-concept. Journal of Humanistic Psychology, 39, 81-105.

Unruh, L., Joseph, L., \& Strickland, M. (2007). Nurse absenteeism and workload: Negative effect on restraint use, incident reports and mortality. Journal of Advanced Nursing, 60, 673-681.

van Beek, I., Taris, T. W., \& Schaufeli, W. B. (2011). Workaholic and work engaged employees: dead ringers or worlds apart? Journal of Occupational Health Psychology, 16, 468-482.

Varma, A., \& Stroh, L. K. (2001). The impact of same-sex LMX dyads on performance evaluations. Human Resource Management, 40, 309-320.

Vinodkumar, M. N., \& Bhasi, M. (2010). Safety management practices and safety behaviour: Assessing the mediating role of safety knowledge and motivation. Accident Analysis \& Prevention, 42, 2082-2093. 
Vinje, H. F., \& Mittelmark, M. B. (2007). Job engagement's paradoxical role in nurse burnout. Nursing \& Health Sciences, 9, 107-111.

Visser, E., Pijl, Y. J., Stolk, R. P., Neeleman, J., \& Rosmalen, J. G. (2007). Accident proneness, does it exist? A review and meta-analysis. Accident Analysis \& Prevention, 39, 556-564.

Vredenburgh, A. G. (2002). Organizational safety: Which management practices are most effective in reducing employee injury rates? Journal of Safety Research, 33, 259276.

Wallace, J. C., Paul, J. B., Landis, R. S., \& Vodanovich, S. J. (2012). Occupational safety. In N. Schmitt (Ed.), The Oxford handbook of personnel assessment and selection (pp. 614-628). New York, NY: Oxford University Press.

Wayne, S. J., Shore, L. M., Bommer, W. H., \& Tetrick, L. E. (2002). The role of fair treatment and rewards in perceptions of organizational support and leadermember exchange. Journal of Applied Psychology, 87, 590-598.

Wrzesniewski, A. (2003). Finding positive meaning in work. In K. S. Cameron, J. E. Dutton, \& R. E. Quinn (Eds.), Positive organizational scholarship: Foundations of a new discipline. San Francisco, CA: Berrett-Koehler.

Wrzesniewski, A., \& Dutton, J. E. (2001). Crafting a job: Revisioning employees as active crafters of their work. Academy of Management Review, 26, 179-201.

Wrzesniewski, A., McCauley, C., Rozin, P., \& Schwartz, B. (1997). Jobs, careers, and callings: People's relations to their work. Journal of Research in Personality, 31, 21-33. 
Yoon, J., \& Lim, J. C. (1999). Organizational support in the workplace: The case of Korean hospital employees. Human Relations, 52, 923-945.

Zacharatos, A., Barling, J., \& Iverson, R. D. (2005). High-performance work systems and occupational safety. Journal of Applied Psychology, 90, 77-93.

Zagenczyk, T. J., Restubog, S. L. D., Kiewitz, C., Kiazad, K., \& Tang, R. L. (2014). Psychological contracts as a mediator between Machiavellianism and employee citizenship and deviant behaviors. Journal of Management, 40, 1098-1122.

Zhang, Z., Wan, D., Jia, M., \& Gu, L. (2009). Prior ties, shared values and cooperation in public-private partnerships. Management and Organization Review, 5, 353-374.

Zohar, D. (2000). A group-level model of safety climate: Testing the effect of group climate on microaccidents in manufacturing jobs. Journal of Applied Psychology, $85,587-596$.

Zohar, D. (2002). The effects of leadership dimensions, safety climate, and assigned priorities on minor injuries in work groups. Journal of Organizational Behavior, 23, 75-92. 
Appendix A

Phase I Study Materials

Interview Protocol - Employee

1. What does your typical workday look like?

2. How often do you have contact with your supervisor? Please describe the extent of this contact in terms of types of information exchanged (i.e., work related questions, non-work related discussions)?

3. Do you feel that your immediate supervisor and other members in the management of the Forest Leadership Team (FLT) are accessible to you if you have questions or concerns about how you do your work?

a. Do you feel that your supervisor and managers support you in your work goals? Do you feel that they create a work environment that supports your safety and your personal health?

4. Do you work in a team or work group? How closely do you work with your team members? Do you feel that they support you in your work goals?

a. Are there times or tasks when you depend more on one another? What are some examples of these?

5. What types of fieldwork teams do you participate in? These would be any work teams away form your office home base. About how many times per month do you participate in fieldwork teams and are they all the same team members doing the same tasks or do they change frequently? What is the average size of a fieldwork team? 6. Are you involved in fire fighting assignments? What is the typical mode of contact for people (e.g., email, snail mail) when they are in the field during the fire season?

7. How current are you on the safety policies of the Agency regarding your work role? Do you feel safety trainings are effective and performed often enough?

a. Does the organization show regular management support for safety (i.e., "walk the talk") and why or why not?

8. What does health mean to you in your work environment? Are you aware of the health programs currently available through the Agency?

a. How do you get information about the incentives and which ones do you use, if any? 


\section{STTEP Interview Protocol - Supervisor}

1. What does your typical workday look like?

2. Describe the structure of the Forest Service around your role? Who are your supervisors, and whom do you report to regularly? Who are on the tiers below you?

3. How often do you have contact with your supervisor? Please describe the extent of this contact in terms of types of information exchanged (i.e., work related questions, non-work related discussions)?

4. Do you feel that your immediate supervisor and other members in the management of the Forest Leadership Team (FLT) are accessible to you if you have questions or concerns about how you do your work?

a. Do you feel that your supervisor and managers support you in your work goals? Do you feel that they create a work environment that supports your safety and your personal health?

5. Do you work in a team or work group? How closely do you work with your team members? Do you feel that they support you in your work goals?

a. Are there times or tasks when you depend more on one another? What are some examples of these?

6. What types of fieldwork do you participate in? About how many times per month do you participate in fieldwork teams and are they all the same team members doing the same tasks or do they change frequently?

7. How do fires impact you in your role?

8. How current are you on the safety policies of the Agency regarding your work role? Do you feel safety trainings are effective and performed often enough?

a. Does the organization show regular management support for safety (i.e., "walk the talk") and why or why not?

b. Are there routine safety meetings? How often are these conducted?

9. What does health mean to you in your work environment? Are you aware of the health programs currently available through the Agency?

a. How do you get information about the incentives and which ones do you use, if any?

10. How likely is it that we can get participation in research activities such as surveys and short training activities during forest fires and how could that differ from participation during non-fire season?

11. What is the typical mode of contact with people during field/fire season? 
Behavior Observation Recording Form

Job Shadowing Protocol

Observer Name:

Subject Name:

Role: Supervisor / Lead /

Non-Supervisor
Date:

Job Title:

Current Context: Lone / Crew / Office
Start Time:

$\overline{\text { End Time: }}$

District:

Typical Context:

Lone / Crew /

Office

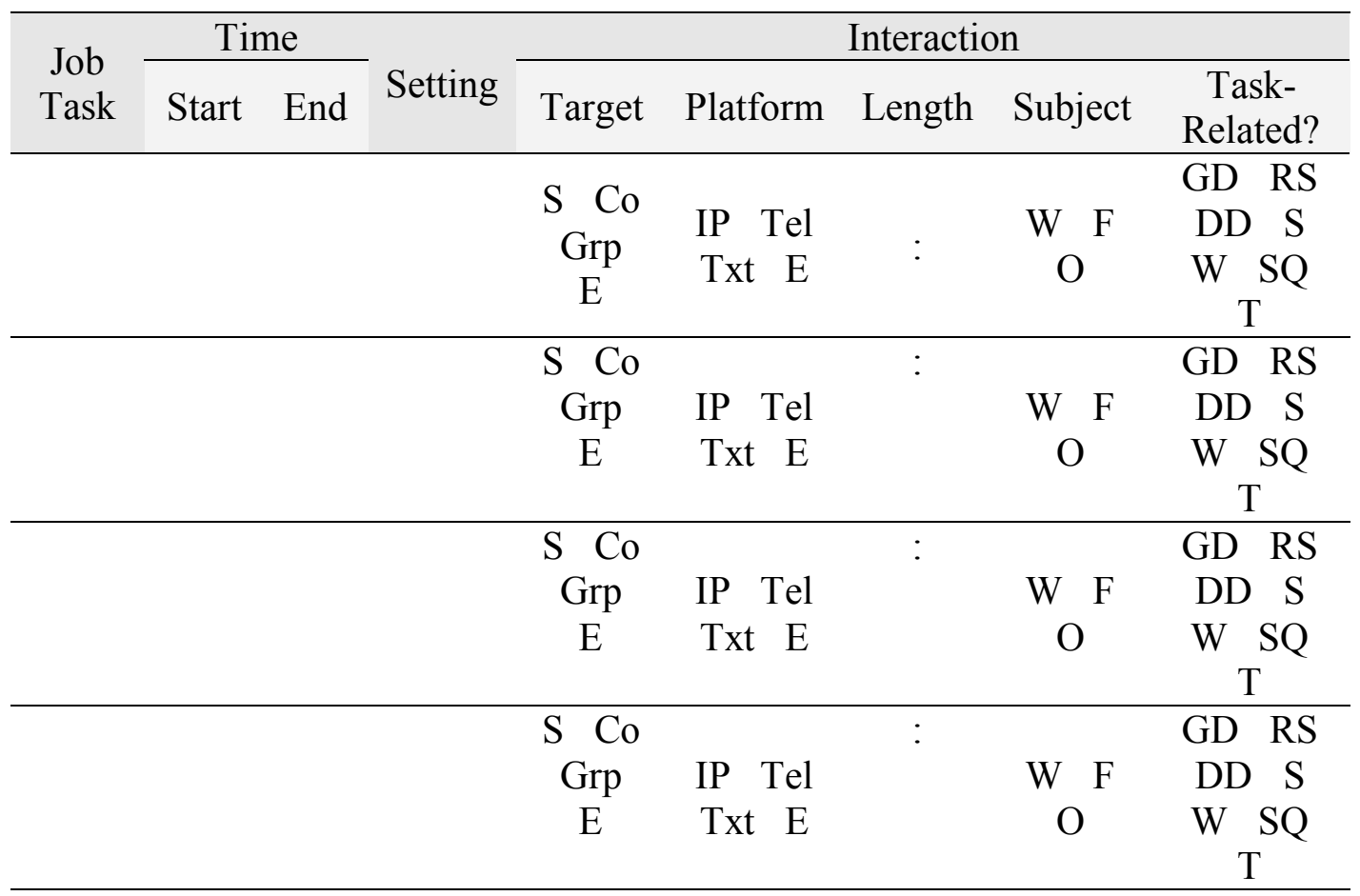

Additional Notes/Comments:

Note. Target: $\mathrm{S}=$ Supervisor, $\mathrm{CO}=$ Coworker, $\mathrm{Grp}=$ Group, $\mathrm{E}=$ Employee/Subordinate; Platform: IP = In-person, Tel = Telephone, Txt $=$ Text, E = Email; Subject: $\mathrm{W}=$ Work, $\mathrm{F}=$ Family, $\mathrm{O}=$ Other; Task-Related Topics: GD = Giving Direction, RS = Requesting Support, DD = Discussion of Duties, $\mathrm{S}=$ Safetyoriented, $\mathrm{W}=$ Wellness-oriented, $\mathrm{SQ}=$ Simple Question, $\mathrm{T}=$ Training. 
Appendix B

Survey Instrument

\section{Demographics}

1. What is your gender?

2. How old are you (in years)?

3. Are you Hispanic/Latino?

4. What is your racial background?

5. What is your level of education completed?

6. What is your current relationship status?

\section{Job Characteristics}

1. When did you start working for the USFS?

2. When did you start working in this forest?

3. How many hours do you work in an average week?

4. Which of these options best describes your job status: Temporary Seasonal, Permanent Seasonal, Permanent Part-time, Permanent Full-time, Volunteer, Other

5. What is your GS level?

6. What District are you stationed in?

7. Are you an active member of the Fire Militia?

8. Your job mainly has to do with: Engineering, Recreation, Firefighting, Natural Resources, Administration, Law Enforcement, Timber Sales, Other

9. You most often work: Alone, With others (team/crew), 50\% alone, 50\% with others

10. You mostly work: Outdoors (in the field), Indoors, 50\% Indoors, 50\% Outdoors

\section{Calling}

1. I am passionate about working for the forest.

2. I enjoy working for the forest more than anything else.

3. Working for the forest gives me immense personal satisfaction.

4. I would sacrifice everything to work for the forest.

5. When I describe myself to others, the first thing I often think about is the work I do with the forest.

6. I would continue my work with the forest even in the face of severe obstacles.

7. I know that the work that I do with the forest will always be a part of my life.

8. I feel a sense of destiny about working with the forest.

9. My work with the forest is always on my mind in some way.

10. Even when not working, I often think about my work with the forest.

11. My existence would be less meaningful without working for the forest.

12. Working with the forest is a deeply moving and gratifying experience for me.

\section{General Supervisor Support}


1. My supervisor can be relied upon when things get tough on my job.

2. My supervisor is willing to listen to my job-related problems.

3. My supervisor cares about my well-being.

\section{Quantitative Workload Inventory (QWI)}

1. How often does your job require you to work very fast?

2. How often does your job require you to work very hard?

3. How often does your job leave you with little time to get things done?

4. How often is there a great deal to be done?

5. How often do you have to do more work than you can do well?

\section{Safety Motivation}

1. I feel that it is worthwhile to put in effort to maintain or improve my personal safety.

2. I feel that it is important to maintain safety at all times.

3. I believe that it is important to reduce the risk of accidents and incidents in the workplace.

\section{Safety Compliance}

1. I use all the necessary safety equipment to do my job.

2. I use the correct safety procedures for carrying out my job.

3. I ensure the highest levels of safety when I carry out my job.

\section{Safety Sensitive Job}

1. Being safe is a key dimension of my job.

2. Impaired performance in my job could create a danger or a safety hazard for my coworkers, the public, or me.

3. Not following safety procedures could create danger or a safety hazard for my coworkers, the public, or me.

\section{Supervisor Support for Safety}

1. My immediate supervisor acknowledges when I work safely.

2. My immediate supervisor tells me when I'm not working safely.

\section{Supervisor Safety Climate}

1. My direct supervisor discusses with us how to improve safety.

2. My direct supervisor uses explanations (not just compliance) to get us to act safely.

3. My direct supervisor refuses to ignore safety rules when work falls behind schedule.

4. My direct supervisor is strict about working safely even when we are tired or stressed.

5. My direct supervisor compliments employees who pay special attention to safety.

6. My direct supervisor frequently talks about safety issues throughout the workweek.

\section{Role Ambiguity}


1. I know exactly what is expected of me.

2. I know that I have divided my time properly.

3. Explanation is clear of what has to be done.

4. I feel certain about how much authority I have.

5. I know what my responsibilities are.

6. Clear planned goals and objectives exist for my job.

\section{Emotional Exhaustion}

1. I feel emotionally drained from my work.

2. I feel used up at the end of the workday.

3. I feel fatigued when I get up in the morning and have to face another day on the job.

4. Working with people all day is really a strain for me.

5. I feel burned out from my work.

6. I feel frustrated by my job.

7. I feel I'm working too hard on my job

8. Working with people directly puts too much stress on me.

9. I feel like I'm at the end of my rope.

\section{Job Satisfaction}

1. In general, you like working at your job.

2. In general, you are satisfied with your job.

3. You are generally satisfied with the kind of work you do in this job.

\section{Work-to-Family Conflict}

1. The demands of my work interfere with my home and family life.

2. The amount of time my job takes up makes it difficult to fulfill family responsibilities.

3. Things I want to do at home do not get done because of the demands that my job puts on me.

4. My job produces strain that makes it difficult to fulfill family duties.

5. Due to work-related duties, I have to make changes to my plans for family activities.

\section{Family-to-Work Conflict}

1. The demands of my family or spouse/partner interfere with work-related activities.

2. I have to put off doing things at work because of demands on my time at home.

3. Things I want to do at work don't get done because of the demands of my family or spouse/partner.

4. My home life interferes with my responsibilities at work such as getting to work on time, accomplishing daily tasks, and working overtime.

5. Family-related strain interferes with my ability to perform job-related duties.

\section{Brief Resilience Scale}

1. I tend to bounce back quickly after hard times

2. I have a hard time making it through stressful events. 
3. It does not take me long to recover from a stressful event.

4. It is hard for me to snap back when something bad happens.

5. I usually come through difficult times with little trouble.

6. I tend to take a long time to get over set-backs in my life.

\section{Decision Making Autonomy}

1. The job gives me a chance to use my personal initiative or judgment in carrying out the work.

2. The job allows me to make a lot of decisions on my own.

3. The job provides me with significant autonomy in making decisions.

\section{Perceived Organizational Support}

1. The Agency values my contribution to its success.

2. The Agency fails to appreciate any extra effort from me.

3. The Agency would ignore any complaint from me.

4. The Agency really cares about my well-being.

5. Even if I did the best job possible, the Agency would fail to notice.

6. The Agency cares about my general satisfaction at work.

7. The Agency shows very little concern for me.

8. The Agency takes pride in my accomplishments at work. 
Appendix C

Post Hoc Analyses

This dissertation was a part of a larger data collection effort. Given the results of the study, it may be worthy to look at the other collected variables to illuminate the relationship that calling may have with other variables. A brief mention of these results is presented in the discussion section but otherwise these post hoc results are not reported in the main body of the paper. Instead these results are illustrated here so to potentially advance the literature on calling. The full survey is listed in Appendix B. A more detailed look at each variable along with a correlation matrix is noted in this Appendix.

\section{Measures}

A number of established measures were used in this study. A description of all measures not mentioned in the body of the text are below.

Safety Sensitive Job. The safety sensitivity of one's job was assessed using Tepper's (1994) three-item measure. A sample item for the scale is "Impaired performance in my job could create a danger or a safety hazard for me, my coworkers, or the public". Participants responded to statements on a 5-point Likert scale $(1=$ Strongly Disagree, 2 = Disagree, $3=$ Neither Agree or Disagree, $4=$ Agree, $5=$ Strongly Agree) . The measure had an alpha of .87. The mean was $4.43(S D=.83)$ indicating that on average participants felt their jobs were safety sensitive. This measure was only collected in two of the three forests, $n=122$.

Supervisor Safety Support. This is a 2-item scale developed Huang, Chen, Krauss, \& Rogers (2004) is used to assess the extent to which respondents believe their 
supervisors encourage and monitor their safety practices at work. A sample item for the scale is "My immediate supervisor tells me when I'm not working safely." Participants responded to statements on a 5-point Likert scale $(1=$ Strongly Disagree, $2=$ Disagree, 3 $=$ Neither Agree or Disagree, $4=$ Agree, $5=$ Strongly Agree). The measure had an alpha of .73 . The mean was $3.50(S D=.94)$ indicating that on average participants felt their supervisors were supportive of safety practices. This measure was only collected in two of the three forests, $n=121$.

Group-level Safety Climate. This 6-item scale measures the degree to which employees think their direct supervisor makes workplace safety a priority (Zohar \& Luria, 2005). A sample item for the scale is "My direct supervisor discusses with us how to improve safety." Participants responded to statements on a 5-point Likert scale $(1=$ Strongly Disagree, 2 = Disagree, $3=$ Neither Agree or Disagree, $4=$ Agree, $5=$ Strongly Agree). The mean was $3.33(S D=.91)$ and the measure had an alpha of .87 .

Role Ambiguity. The 6-item measure developed by Rizzo, House, \& Lirtzman (1970) was used to measure the amount of uncertainty that an employee may feel regarding the expectations and/or behaviors associated with a certain job or position. A sample item for the scale is "I know exactly what is expected of me." Participants responded to statements on a 5 -point Likert scale $(1=$ Strongly Disagree, $2=$ Disagree, 3 $=$ Neither Agree or Disagree, $4=$ Agree, $5=$ Strongly Agree $).$ The mean was $2.27(S D=$ $.85)$ and the measure had an alpha of .90. In this case, higher numbers indicate less ambiguity. 
Emotional Exhaustion. Emotional exhaustion was measured by Maslach \& Jackson's 9-item scale. A sample item for the scale is "I feel emotionally drained from my work." Participants responded to statements on a 5 -point Likert scale $(1=$ Strongly Disagree, 2 = Disagree, 3 = Neither Agree or Disagree, $4=$ Agree, $5=$ Strongly Agree). The mean was $3.00(S D=.93)$ and the measure had an alpha of .92. This measure was only collected in two of the three forests, $n=122$.

Job Satisfaction. Job satisfaction was assessed with a 3-item scale (Cammann, Fichman, \& Klesh, 1983). A sample item for the scale is "In general, I like working at my job." Participants responded to statements on a 5-point Likert scale $(1=$ Strongly Disagree, $2=$ Disagree, $3=$ Neither Agree or Disagree, $4=$ Agree, $5=$ Strongly Agree) . The mean was $4.00(S D=1.00)$ and the measure had an alpha of .88 .

Work-to-Family Conflict (WFC) and Family-to-Work Conflict (FWC). WFC and FWC were assessed with a 10-item scale (Netemeyer et al., 1996). A sample item for the WFC scale is "The demands of my work interfere with my home and family life." The mean for WFC was $3.91(S D=1.65)$ and the measure had an alpha of .93. A sample item for the FWC scale is "The demands of my family or spouse/partner interfere with workrelated activities." The mean FWC was $2.46(S D=1.17)$ and the measure had an alpha of .90. For both measures participants responded to statements on a 7 -point Likert scale $(1=$ Strongly Disagree, 2 = Disagree, 3 = Somewhat Disagree, $4=$ Neither Agree or Disagree, $5=$ Somewhat Agree, $6=$ Agree, $7=$ Strongly Agree $)$.

Brief Resilience Scale. The brief resilience scale (BRS) is a 6-item scale created to assess the ability to bounce back or recover from stress (Smith, Dalen, Wiggins, Tooley, 
Christopher, \& Bernard, 2008). A sample item for the scale is "I tend to bounce back quickly after hard times." Participants responded to statements on a 5-point Likert scale $(1=$ Strongly Disagree, $2=$ Disagree, $3=$ Neither Agree or Disagree, $4=$ Agree, $5=$ Strongly Agree). The mean was $3.78(S D=.80)$ and the measure had an alpha of .89 . This measure was only collected in two of the three forests, $n=122$.

Decision-Making Autonomy. Decision-making autonomy was assessed with the Morgeson and Humphrey's 3-item scale. A sample item for the scale is "The job gives me a chance to use my personal initiative or judgment in carrying out the work." Participants responded to statements on a 5-point Likert scale $(1=$ Strongly Disagree, $2=$ Disagree, $3=$ Neither Agree or Disagree, $4=$ Agree, $5=$ Strongly Agree). The mean was $4.00(S D=.95)$ and the measure had an alpha of .88 . This measure was only collected in two of the three forests, $n=122$.

Perceived Organizational Support (POS). POS was measured with the Eisenberger, Huntington, Hutchison, and Sowa's 8-item scale. A sample item for the scale is "The Agency values my contribution to its success." Participants responded to statements on a 7-point Likert scale $(1=$ Strongly Disagree, $2=$ Disagree, $3=$ Somewhat Disagree, $4=$ Neither Agree or Disagree, $5=$ Somewhat Agree, $6=$ Agree, $7=$ Strongly Agree). The mean was $4.37(S D=1.29)$ and the measure had an alpha of .90 . 
Table 11

Means, standard deviations, and correlations of study variables and other collected variables

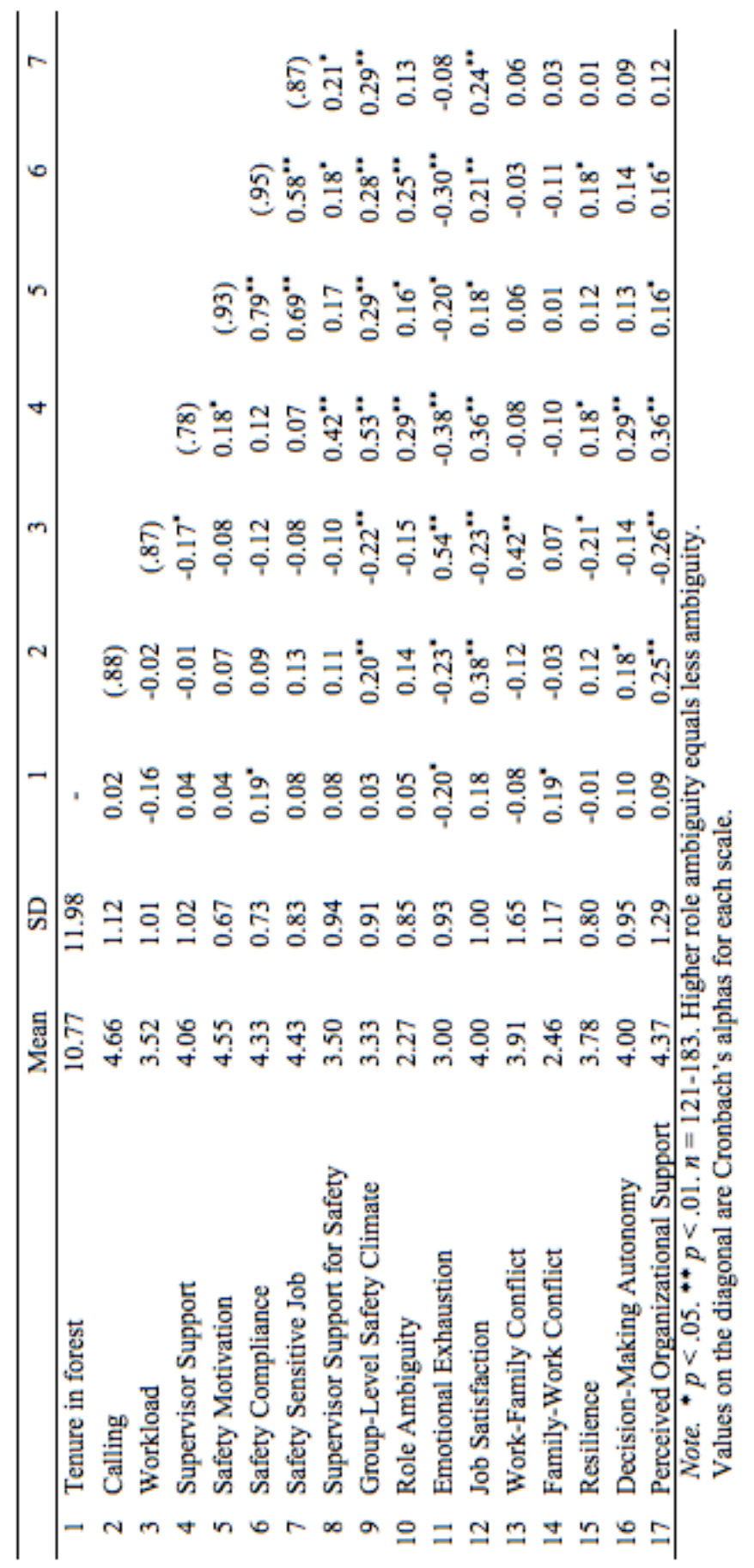


Means, standard deviations, and correlations of study variables and other collected variables (cont.)

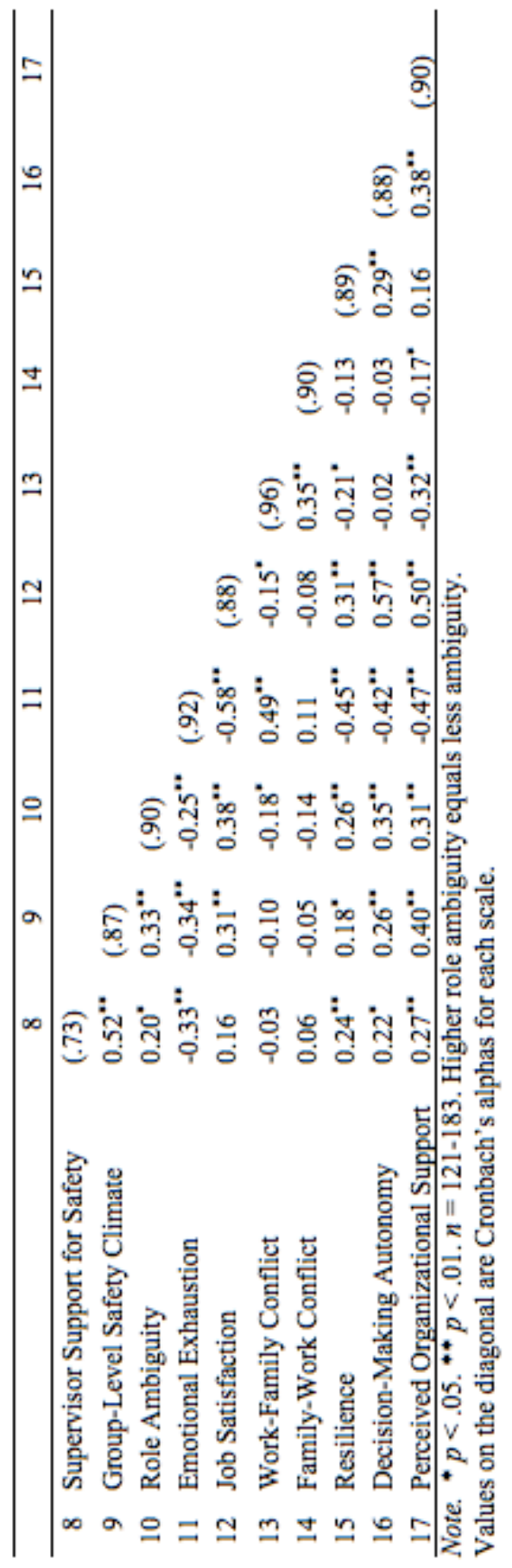

